Key Words:

Environment

Remediation

Retention:

Permanent

\title{
CHARACTERIZATION AND MONITORING OF NATURAL ATTENUATION OF CHLORINATED SOLVENTS IN GROUND WATER: A SYSTEMS APPROACH
}

AUGUST 2006

Washington Savannah River Company Savannah River Site Aiken, SC 29808 


\section{DISCLAIMER}

Preparation of this report was coordinated by Washington Savannah River Company (WSRC) for the United States Department of Energy (US DOE) under Contract No. DEAC09-96SR18500. Extensive effort was made by the authors to assure the accuracy of the contents and interpretation. However, the USDOE nor WSRC, nor any of their employees makes any warranty, expressed or implied, or assumes any legal liability or responsibility for accuracy, completeness, or usefulness, of any information, apparatus, or product or process disclosed herein or represents that its use will not infringe privately owned rights. Reference herein to any specific commercial product, process, or service by trade name, trademark, name, manufacturer or otherwise does not necessarily constitute or imply endorsement, recommendation, or favoring of same by Washington Savannah River Company or by the United States Government or any agency thereof. The views and opinions of the authors expressed herein do not necessarily state or reflect those of the United States Government or any agency thereof.

Printed in the United States of America

Prepared For

U.S. Department of Energy 
Key Words:

Environment

Remediation

Retention:

Permanent

\title{
CHARACTERIZATION AND MONITORING OF NATURAL ATTENUATION OF CHLORINATED SOLVENTS IN GROUND WATER: A SYSTEMS APPROACH
}

\author{
Tyler Gilmore, Pacific Northwest National Laboratory (PNNL) \\ Brian B. Looney, Savannah River National Laboratory (SRNL) \\ Norman Cutshall (Technical Consultant) \\ David Major, GeoSyntec, Inc. \\ Todd Wiedemeier, T.H. Wiedemeier \& Associates, LLC \\ Francis H. Chapelle, U.S. Geological Survey \\ Michael Truex, PNNL \\ Tom Early, Geo Consultants, LLC \\ Michael Heitkamp, SRNL \\ Jody Waugh, S. M. Stoller \\ David Peterson, S.M. Stoller \\ Gary Wein, Bechtel Savannah River Inc. \\ Christopher Bagwell, SRNL \\ Mark Ankeny, Idaho National Laboratory \\ Karen M. Vangelas, SRNL \\ Karen M. Adams, U.S. Department of Energy \\ Claire H. Sink, U.S. Department of Energy
}


WSRC-STI-2006-00084, Rev. 1

August 1, 2006

Page iii of xi

\section{Errata}

References have been updated to reflect revisions to supporting documents.

Page 48. Early et al, 2006 reference updated to reflect amended document. Now is Rev. 1.

Page 50. Provides updated reference for Looney et al, 2006. 


\section{FOREWORD}

In 2003, the U.S. Department of Energy (DOE) Office of Environmental Management authorized an alternative project designed to develop cost-effective and environmentally protective technical solutions for the challenge posed by large and complex plumes of chlorinated volatile organic compounds (CVOCs) in ground water at the Savannah River Site. The project builds on the current U.S. Environmental Protection Agency (EPA) directive and protocol (EPA 1998, 1999) for monitored natural attenuation (MNA). The DOE effort uses a systems approach to address three major technical areas: mass balance, enhanced attenuation (EA), and advanced characterization/monitoring. Each of these three topics is supported by a broadly based group of recognized technical experts. This report is one of three currently being prepared by the group. By promoting the concepts of mass balance and EA, along with the technical basis and documentation for these concepts, the project pursues a goal of providing powerful new tools that facilitate the transition from active remediation to a protective passive environmental management strategy that includes efficient long-term monitoring. This project is a departure from classical MNA in that its central theme is to work proactively to achieve a favorable balance between the release of contaminants from sources (source loading) and processes that destroy or retard migration of contaminants in resultant plumes (attenuation capacity of the system).

Acknowledgement: Several authors contributed significantly to this document. The authors are grateful to Mike Barcelona, Mark Ferrey, Paul Johnson, and several members of the Interstate Technology and Regulatory Council (ITRC) Enhanced Attenuation: Chlorinated Organics Team who made many constructive comments and suggestions on a draft version. An attempt has been made to address those comments. Any omissions or errors that remain are the responsibility of the authors.

\section{OBJECTIVES}

The objective of this document is to examine the use of a phased approach to characterizing and monitoring $(\mathrm{C} \& \mathrm{M})$ natural attenuation processes and enhanced attenuation processes and to identify promising tools and techniques by which to accomplish the C\&M. We will investigate developing techniques, such as molecular-based assessment tools, and existing tools that traditionally have not been used for monitoring the performance of environmental remediation technologies. Case studies will be used to provide examples of how non-traditional methods are being employed as characterization and monitoring tools to support MNA and EA.

The document is not focused on a specific group of readers but rather is broadly directed with the intent that readers may gain information useful to their purposes. Thus, regulators may see some future characterization and monitoring techniques; end users may find novel ways to make MNA or EA more effective or efficient at their site; researchers may identify new areas for development or new and better combinations of existing methods. One consequence of this broad approach is that some readers may find certain sections either too rudimentary or too advanced for their needs. Hopefully, all will be able to use at least some of the document. 


\section{ORGANIZATION OF THIS REPORT}

Page v of xi

This paper focuses on approaches designed to improve the current baseline method for C\&M sites where natural attenuation is selected for remediation. The first four sections are devoted to overarching conceptual approaches to MNA and define the context for the later sections. The first section describes the role of characterization and monitoring in MNA. The second section describes a phased approach to characterization and monitoring that is intended to comprehensively define the MNA process from start to end and be used in conjunction with the regulatory guidance. The next two sections describe the use of a mass balance approach as the central concept for characterization and monitoring.

Sections 5.0 and 6.0 are a review of new or developing techniques that appear to hold promise for C\&M.. These sections are intended to support these overarching concepts by including more direct measures of attenuating mechanisms and promoting non-traditional long-term monitoring approaches. NOTE: Readers who are interested only in new developments may wish to skip the contextual material in Sections 1.0-4.0 and focus directly on Sections 5.0-6.0. The new developments, however, can best be appreciated in the context of Sections 1.0-4.0. 


\section{Contents}

Forward

Objectives

Organization of the Report $\quad \mathrm{V}$

List of Acronyms $\quad$ ix

Glossary

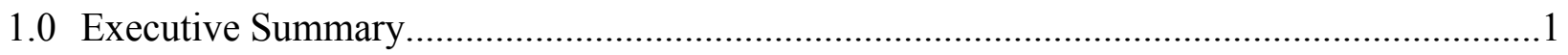

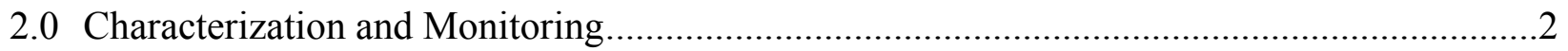

3.0 Phased Approach to Characterization and Monitoring ......................................................3

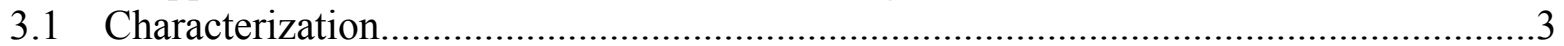

3.2 Transition Between Phases........................................................................................

4.0 Synopsis of Original Protocol …............................................................................... 7

4.1 Multiple Lines of Evidence ................................................................................... 7

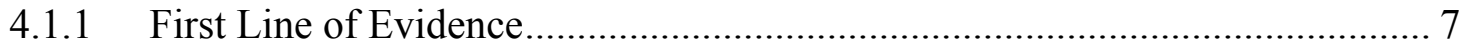

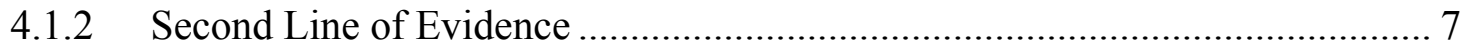

4.1.3 Third Line of Evidence ...................................................................... 8

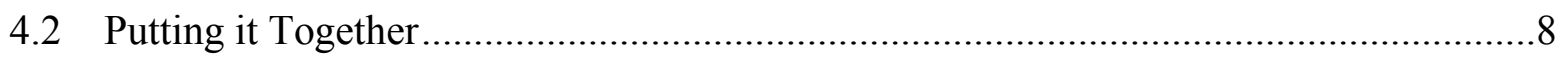

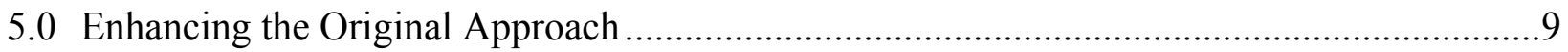

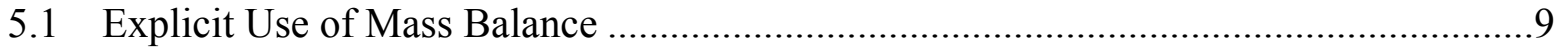

5.2 Empirical/Deterministic Approach............................................................... 10

5.3 Deterministic Approach and Enhanced Attenuation ...........................................11

6.0 Developing Techniques and Concepts for Characterization ..........................................14

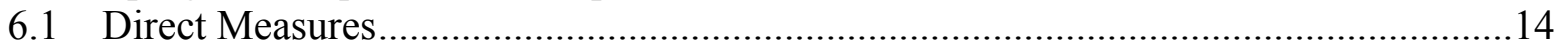

6.1.1 Direct Measures of Biodegradation ........................................................ 17

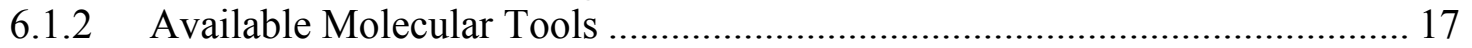

6.1.3 Direct Measures of Flux........................................................................... 21

6.2 Current Methods for Estimating Contaminant Flux .................................................22

6.3 Direct Measure of Advective Flow .....................................................................24

7.0 Developing Techniques and Concepts for Monitoring .................................................27

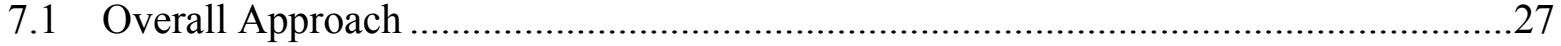

7.2 Conceptual Development of Performance Monitoring ..............................................28

7.3 Transition from Process to Performance Monitoring ................................................29

7.3.1 Monitoring Configuration/Optimization............................................... 29

7.3.2 Streamlined Compliance Monitoring and Reporting ................................... 30

7.4 Technologies and Concepts to Advance Performance Monitoring .............................32

7.4.1 Indicator Parameters ....................................................................... 32 
7.4 .2 Phytomonitoring ...............................................................

Page vii of xi

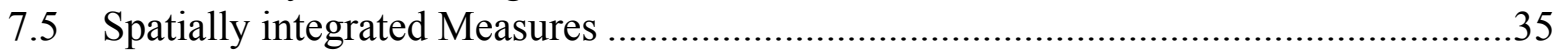

7.5.1 Geophysical Methods in Monitoring MNA ............................................... 35

7.5.2 Accumulators/Integrative Samplers .................................................... 38

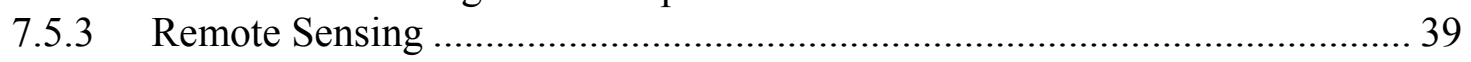

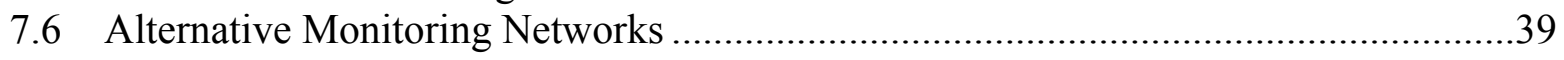

7.6.1 Alternate Well Geometries, Horizontal Wells .............................................. 39

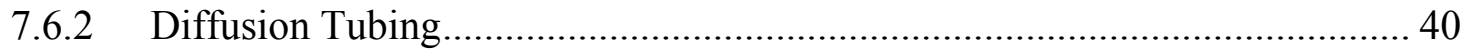

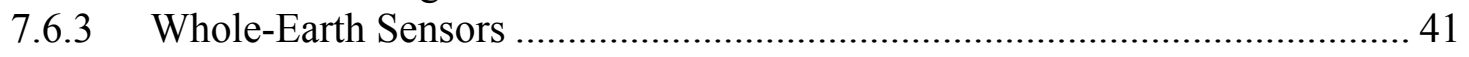

7.6.4 Self-Checking (Safe Positive) Sensor Systems......................................... 41

7.6.5 Potential Alternative to Spatially integrated Measures............................... 42

8.0 Technical Targets and Conclusions ...........................................................................43

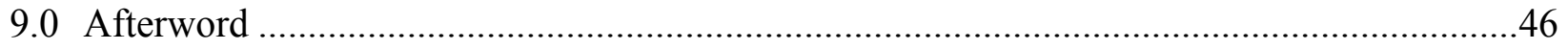

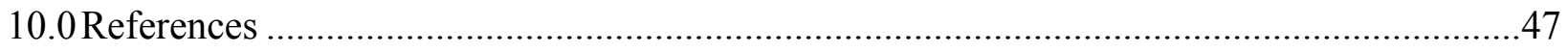

\section{Figures}

3.1 Phased Approach to Characterization and Monitoring Monitored Natural Attenuation ........4

3.2 Correlation of the MNA Project Systems Approach with CERCLA ................................6

5.1 Mass Balance Between Contaminant Loading and System Capacity .............................10

\section{Tables}

6.1 Summary of Important Processes for Mass Balance Calculation ....................................15

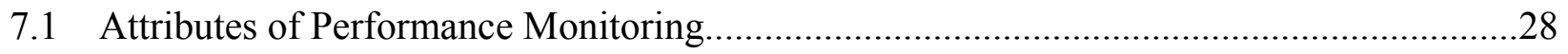

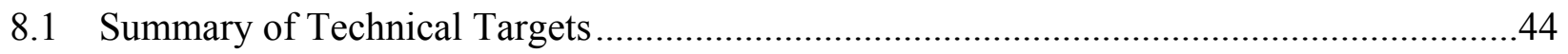




\section{Case Studies}

5.1: Selecting Remediation Goals by Assessing the Natural Attenuation Capacity of Groundwater Systems (Chapelle and Bradley 1999)

5.2: Use of the Deterministic Approach for Calculating a Mass Balance in Developing a Site Long-Term Monitoring Plan (Truex et al. 2002)......................................................................13

6.1: Assessing Natural Degradation with In Situ Microcosms ............................................. 18

6.2: Development of Molecular Tools for Environmental Work .............................................19

6.3: Directly Measuring Groundwater Flow ....................................................................26

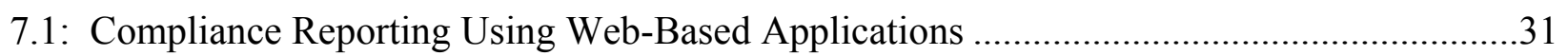

7.2: Monticello, Utah, Superfund Site a Case Study in Use of Indicator Parameters ...................33

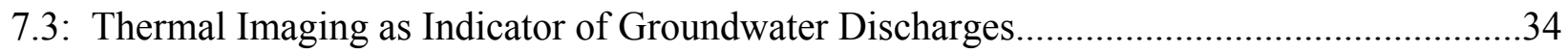

7.4: Estimating Redox Potential from Self-Potential Measurements ........................................37

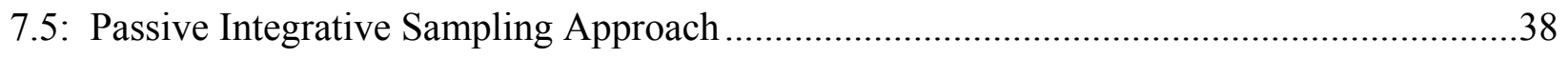

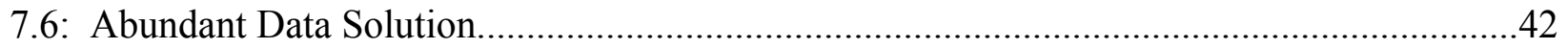




\section{LIST OF ACRONYMS}

$\begin{array}{ll}\text { ACO } & \text { ant colony optimization } \\ \text { ARS } & \text { aerial remote sensing } \\ \text { BFSD } & \text { benthic flux-sampling device } \\ \text { cDCE } & \text { cis-1,2-dichloroethene } \\ \text { CFM } & \text { BUTE chlorophyll fluorometer } \\ \text { C\&M } & \text { characterizing and monitoring } \\ \text { cPCR } & \text { see qPCR } \\ \text { CVOC } & \text { chlorinated volatile organic compounds } \\ \text { DC } & \text { direct current } \\ \text { DNA } & \text { deoxyribonucleic acid } \\ \text { DOE } & \text { U.S. Department of Energy } \\ \text { EA } & \text { enhanced attenuation } \\ \text { EPA } & \text { U.S. Environmental Protection Agency } \\ \text { ESTCP } & \quad \text { Environmental Security Technology Verification Program } \\ \text { ET } & \text { evapotranspiration } \\ \text { iMF } & \text { integrated mass flux } \\ \text { IP } & \text { induced polarization } \\ \text { ISM } & \text { in situ microcosms } \\ \text { ISPF } & \text { in situ permeable flow } \\ \text { ITRC } & \text { Interstate Technology and Regulatory Council } \\ \text { LAI } & \text { leaf area index } \\ \text { LDPE } & \text { a type of deployed diffusion tubing } \\ \text { MNA } & \text { monitored natural attenuation } \\ \text { (m)RNA } & \text { messenger RNA } \\ \text { NCBI } & \text { National Center for Biotechnology Information } \\ \text { PCE } & \text { perchloroethene } \\ \text { PCR } & \text { polymerase chain reaction } \\ \text { qPCR } & \text { quantitative polymerase chain reaction } \\ \text { RCRA } & \text { Resource Conservation and Recovery Act } \\ \text { RDP } & \text { Ribosomal Data Project } \\ \text { RNA } & \text { ribonucleic acid } \\ \text { SERDP } & \text { Strategic Environmental Research and Development Program } \\ \text { SP } & \text { self-potential } \\ \text { SPMD } & \text { semipermeable membrane devices } \\ \text { TDR } & \text { time domain reflectometry } \\ \text { TIR } & \text { thermal infrared } \\ \text { TOC } & \text { total organic carbon } \\ \text { VOC } & \text { volatile organic compound } \\ & \end{array}$




\section{GLOSSARY}

abiotic degradation - chemical and/or transformations that degrade contaminants without the presence of microorganisms

advection - movement of solute by bulk groundwater motion

attenuate - cause to become weaker, in strength, value, or magnitude

characterization - provide evidence that determines whether or not attenuation capacity in the system is sufficient and sustainable

biodegradation - decomposition of organic material by microorganisms

desorption - changing from an adsorbed state on a surface to a gaseous or liquid state

deterministic approach - using a computer simulation to predict environmental response.

Processes based on assumptions that "events proceed in a fixed predictable fashion.

diffusion - spreading and dilution of contaminant due to molecular diffusion

dispersion - fluid mixing due to groundwater movement and aquifer heterogeneities

downgradient - the direction that groundwater flows; similar to downstream for surface water

empirical approach - information derived from observation or experiment

enhanced attenuation - actions taken to make natural attenuation processes operate more rapidly or completely

flux - rate of flow of fluid, particles, or energy through a given surface

heterogeneity - diversity of subsurface properties

hydrogeology - the study of rocks that deals with the distribution and movement of groundwater in the soil and rocks

hydraulic conductivity - property of soil or rock in the vadose zone or groundwater that describes the ease with which water can move through pore spaces or fractures (mathematically represented as $K$ )

hydraulic head - measure of potential energy in groundwater in an aquifer

lysimeter - device for measuring gains (precipitation and condensation) and losses (evapotranspiration) of water by a column of soil

mass balance - quantifying the amount of material going into and out of a process, where the difference between input and output is assumed to be attenuated within the system

microarray - a multifaceted tray or array of DNA material. Microarrays are expected to revolutionize medicine by helping pinpoint a very specific disease or the susceptibility to it. Sometimes called "biochips," micro arrays are commonly known as "gene chips." 
WSRC-STI-2006-00084, Rev. 1

August 1, 2006

Page xi of xi

monitoring - verify the attenuation capacity is maintained over time and as conditions vary or remediation goals are met

natural attenuation - the ability of the earth to rid itself of contamination phylogenetic - based on evolutionary development or history

phytomonitoring - using plants to monitor a contaminant site

recharge - movement of water through the vadose zone into the saturated zone

resistivity - measure of a material's resistance to current flow

sorption - reaction between aquifer matrix and solute whereby relatively hydrophobic organic compounds are bound by organic carbon or clay minerals

taxonomy - classification of organisms into an ordered system

volatilization - contaminants dissolved in groundwater change into the vapor phase (soil gas) 


\subsection{Executive Summary}

The groundwork for this paper is the original EPA Technical Protocol for Evaluating Natural Attenuation of Chlorinated Solvents (EPA 1998). The EPA protocol introduced a process to evaluate the efficiency of MNA. It transformed the approach to cleaning up contaminated sites by acknowledging that the earth has a significant capacity to renew itself and that this capacity should be utilized where appropriate. Since the original protocol was published in 1998, a great deal of experience has been gained in its application and advances have been made to the science of characterization and monitoring. The intent of this paper is not to repeat or re-work previous advances but to build on them.

The following specific advances are highlighted in this paper:

- Phased approach to characterization and monitoring

- Explicit use of mass balance to guide characterization/monitoring

- Combined empirical and deterministic methods for complex sites

- Improvements in direct measures of attenuation (e.g., bioassay, contaminant flux)

- Consideration of non-traditional long-term monitoring approaches

Characterization and monitoring are at the heart of MNA. Even though these two terms are sometimes used interchangeably, they represent distinct functions to first define and then verify the performance of the natural attenuation processes. This paper presents a strategy for characterization and monitoring in a four-phased approach. The strategy facilitates application of the right methods and tools at the proper times. This approach emphasizes the need to begin planning for the monitoring phases earlier in the process as part of a more cost-effective approach to monitoring design and implementation.

Remediation alternatives that rely on natural mechanisms ultimately depend on the attenuation capacity of the system - the sum of the various mechanisms must be sufficient to attenuate the contaminants and protect potential receptors. This concept of a mass balance between the loading and attenuation of contaminants in a groundwater system provides both a framework for characterization and monitoring and an effective way to conceptualize, document and communicate an MNA approach.

Research into new approaches and tools for monitoring is needed to limit future costs of longterm performance monitoring. Currently, long-term monitoring costs at DOE sites are often projected to exceed the cleanup costs. There is a need to move away from adapting by default the "detection monitoring well" networks as the long-term performance-monitoring network. Although the intensity and cost of long-term monitoring are expected to decline with time, the criteria for reducing efforts need to be better defined. This paper identifies the attributes of a performance-monitoring network and offers concepts to promote the development of new strategies and approaches to performance monitoring networks. 


\subsection{Characterization and Monitoring}

Every natural system has a capacity to attenuate environmental contaminants through a variety of physical, chemical, and biological processes and the final stages of remediation must rely on this capacity. It is therefore important to understand and measure the natural processes that will achieve final remediation of contaminated sites. Characterization is needed to identify and estimate the contribution of the most important attenuating mechanisms and enable comparison of contaminants loading to attenuation. This comparison provides the basis for determining the adequacy of natural attenuation for a site. If characterization indicates the system has enough "natural" capacity then MNA may be deemed appropriate for the site. Subsequent monitoring verifies the effectiveness of attenuation or warns of failures.

A significant amount of work has been devoted to monitoring and characterization for MNA. The intent of this paper is not to repeat or re-work previous efforts but to build on them and focus on areas where there is opportunity for advancement. The groundwork for this paper is the original EPA Technical Protocol for Evaluating Natural Attenuation of Chlorinated Solvents (EPA 1998). This protocol introduced a process for evaluating the efficacy of MNA at a particular site. Since the original protocol was published in 1998, a great deal of experience has been gained and advances have been made in the science of characterization and monitoring. Recently, EPA developed substantive supplementary guidance, Performance Monitoring of MNA Remedies for VOCs in Ground Water (EPA 2004a). The newer guidance focuses on important spatial and temporal issues and statistics to help interpret data. EPA (2004a) emphasizes the need to monitor for "changes" and identify the conditions that would trigger a need to implement contingency measures. Several tools and processes highlighted below support the ideas in EPA's technical protocol (EPA 1998) and performance monitoring document (EPA 2004a). These include:

- Phased approach to characterization and monitoring that provides a framework

- Explicit use of mass balance to guide characterization/monitoring

- Deterministic methods for complex sites

- Improvements in direct measures of attenuation (e.g., bioassay, contaminant flux)

- Consideration of non-traditional long-term monitoring approaches 


\subsection{Phased Approach to Characterization and Monitoring}

Characterization and monitoring can be organized into four sequential phases: (1) screening characterization, (2) decision characterization, (3) process monitoring, and (4) system performance monitoring (Figure 3.1). This approach is designed to focus the evaluation and application of MNA by identifying the essential and cost-efficient monitoring tools, methods, and processes for each phase.

The phased approach is not intended to supplant State or Federal regulatory guidance, but is intended to comprehensively assist the MNA process in conjunction with existing guidance. This approach parallels the 'tiered approach' EPA uses for MNA (EPA 2004b).

Most interest in MNA has focused on upfront characterization to determine if MNA is viable. Less focus has been placed on monitoring; it is commonly addressed after a remedy is selected and is commonly an extension of measuring the parameters collected during characterization. The four-phased approach presented here promotes the development of the system performance or long-term monitoring (phase IV) by identifying the key factors controlling the natural attenuation capacity of the system during the process monitoring (phase III).

\subsection{Characterization}

Characterization falls into two distinct phases, screening and decision. Although each phase has specific goals, the overall goal of characterization is to determine if the site is appropriate for MNA. If the site is not appropriate for MNA, the characterization phases are also designed to determine what combination of enhancements, source removal, or engineered solutions are necessary.

In the screening characterization phase, the extent and location of the primary source, the contaminant loading and the attenuating mechanisms are estimated. Also during this phase a site conceptual model is developed. Conceptual model assessment may also involve screening of possible future scenarios. The conceptual model will guide future characterization and monitoring efforts and can be updated as needed. At some sites, the screening characterization phase will be straightforward, particularly where one or two primary attenuating mechanisms provide enough attenuation capacity. At the other extreme, MNA may not be feasible.

The decision characterization phase is a more detailed effort intended to enable complete evaluation of the natural attenuation processes to support selection of MNA. In this phase, a more detailed estimate of the system mass balance is determined in terms of system capacity and contaminant loading. The attenuating mechanisms, their rates, and an estimate of sustainability are identified. This phase provides the information to make a decision either (1) select MNA as a remedy (2) consider EA in conjunction with MNA or (3) reject MNA and use another remediation technique. This phase in some cases is the most difficult because a "preponderance" of evidence is often required to support the MNA decision. Some of the technical targets presented in this paper address this issue, most notably the development of more direct measures of attenuation (Section 7.0). 
WSRC-STI-2006-00084 Rev. 1

August 1, 2006

Page 4 of 53

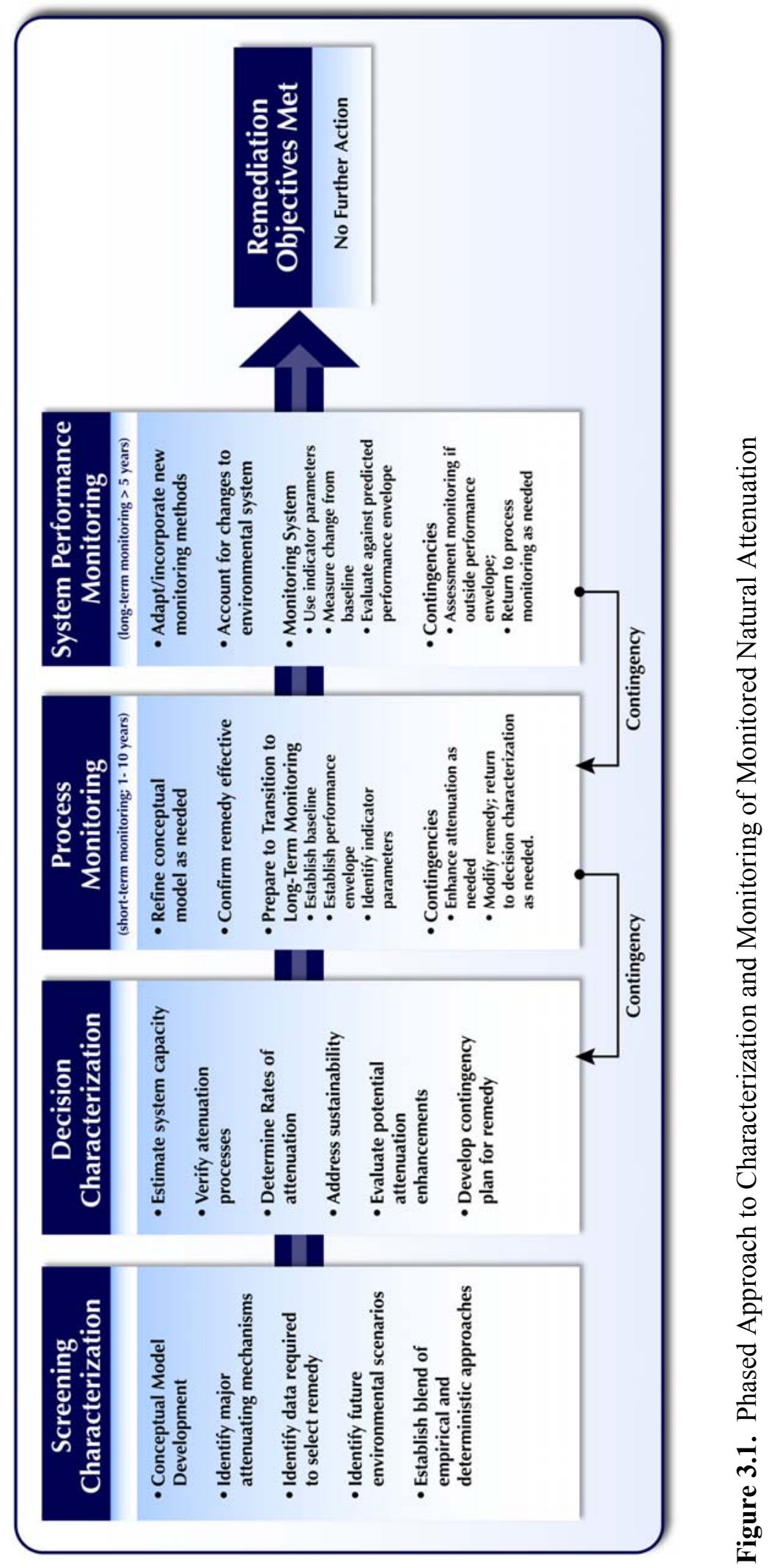


Characterization will be converted to monitoring once a remedy has been selected. The first phase of monitoring, process monitoring, will be used to verify that the remedy is working as intended. In this phase, attenuation capacities and rates determined in the characterization stage are confirmed in order to validate the planned remedy. This type of monitoring, initially very important, can become expensive if continued for a long period of time. Therefore, it is important to collect data that will allow a transition to systems performance monitoring, also called long-term performance or verification monitoring. This will involve (1) establishing a baseline for the plume conditions including the range or "performance envelope" within the plume and (2) identifying indicator parameters that can be used in place of comprehensive suites of parameters for monitoring.

The purpose of systems performance monitoring is to assess the long-term function of the remedy. Systems performance monitoring is the primary activity in long-term stewardship. The foundation of systems performance monitoring will be to monitor indicator parameters and compare them to the established baseline conditions to determine if plume conditions are within the established "performance envelope". This concept is equivalent to the assessment monitoring in the Resource Conservation and Recovery Act (RCRA 1976). Contingency plans for both detailed assessment monitoring and a contingency plan to enhance the remediation if necessary should have been prepared for this situation.

The systems performance monitoring stage will in many applications be the longest in duration. It will, therefore, be important to make the monitoring process as efficient as possible. To accomplish this efficiency, the focus of system performance monitoring should be on the system (plume and environmental setting) as a whole. Measured flux or documented stresses to the ecological system are more useful than point measurements in wells. System performance monitoring can usually be most efficient by focusing on indicator parameters, particularly spatially integrated indicator parameters. Development of alternative monitoring techniques and configurations to cost-effectively meet the objectives of system performance monitoring is a current need (see Section 8.0).

The four phases discussed above are well correlated with the schedules of the CERCLA process as shown in Figure 3.2.

\subsection{Transition Between Phases}

Transitions between characterization and monitoring phases are critical steps; their timing must be well planned and linked to analysis of results. It is important that the transitions be supported by consideration of data and also be appropriately timed. Transitions that are perceived as premature could elicit resistance from stakeholders or regulators and lead to rejection of MNA solutions. On the other hand, transitions need to occur as early as is reasonably possible both to expedite remediation and to control cost. The transition from process monitoring to systems performance monitoring is especially critical. Whereas process monitoring is likely to be data intensive in order to support multiple lines of evidence, systems performance monitoring should rely on a reduced number and frequency of observations. It may require non-traditional monitoring tools. 
Commonly, characterization and monitoring rely on an array of wells and these "detection" wells by default often become the long-term monitoring network. Current approaches that gradually reduce the number of samples and sampling locations through optimization, data quality objective approaches, combining contiguous waste sites, and automated networks may eventually be replaced by configurations that do not depend on well-networks at all. An ecosystem approach in which larger scale perturbations are monitored and compared to a baseline may be most effective for long-term monitoring (see Section 7.0).

MNA/EA Project System's Approach

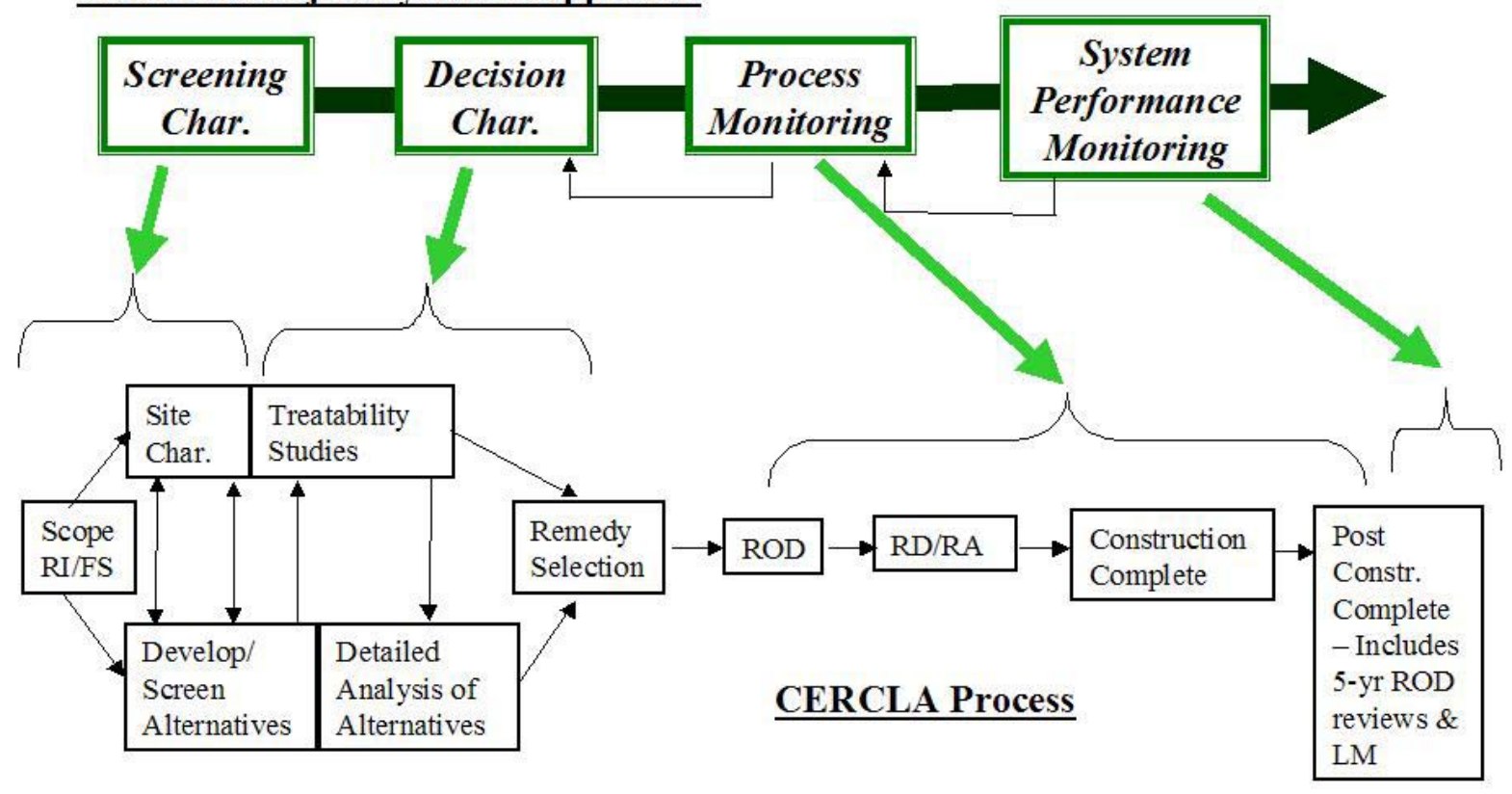

ROD - Record of Decision

RD/RA - Remedial Design/ Remedial Action

Figure 3.2. Correlation of the MNA/EA Project System Approach with CERCLA 


\subsection{Synopsis of Original Protocol}

Recognition, evaluation, and reliance on natural attenuation processes for remediation and final polishing of contaminated sites have been the focus of substantial scientific and policy efforts over the past twenty years. As discussed in this section, the well- crafted protocols developed during the 1990s and published by EPA (EPA 1998) successfully blended the needs of practicality, discipline, and environmental goals. As a result, the protocols were major milestones in development of national environmental policies. The strength of the protocols was reliance on "multiple lines of evidence." Lines of evidence were graded from concentration observations (over time and space), through indirect geochemical indicators, to site-specific confirmation as needed (e.g., using microcosms). The first two lines of evidence relied on empirical data. The quantity and type of evidence required for any site was determined in part, by the strength of the previous line of evidence. For example, if the concentration data and geochemistry were compelling, sites advanced into monitored natural attenuation.

\subsection{Multiple Lines of Evidence}

Current federal guidelines for chlorinated volatile organic compounds (CVOC) (EPA 1998, 1999) identify three tiers of site-specific information or "lines of evidence" to evaluate the efficacy of MNA as a potential remedy. These lines of evidence are summarized as follows:

- First Line of Evidence. Historical groundwater data that demonstrate a clear and meaningful trend of decreasing contaminant mass and/or concentration over time/distance and the presence of daughter products at appropriate monitoring points.

- Second Line of Evidence. Hydrogeologic and geochemical data that can be used to demonstrate indirectly the type(s) of natural attenuation processes at the site and the rate at which such processes will reduce contaminant concentrations to required levels.

- Third Line of Evidence. Other information, such as data from field or microcosm studies, which directly demonstrates or quantifies the occurrence of a particular natural attenuation process and its ability to degrade contaminants of concern.

\subsubsection{First Line of Evidence}

The analysis of the first line of evidence typically involves constructing concentration versus time data at monitoring locations within the contaminant plume. Specific recommendations for interpretation are spelled out in the detailed regulatory guidance documents (e.g., Newell et al. 2002) developed to augment the overarching policy documents (EPA 1998, 1999).

\subsubsection{Second Line of Evidence}

Natural attenuation assessments involve an analysis of spatial and temporal trends in organic pollutant concentrations and in geochemical conditions. This constitutes the second line of evidence. An analysis of spatial and temporal trends based on tabulated data is tedious. Further, it is often difficult for such evaluation to compellingly support natural attenuation. Individual chemical contour maps may be difficult to generate because of site heterogeneity or sparse data. It may be difficult to visualize correlation between trends in organic pollutants and geochemical 
indicator concentrations by examining multiple contour maps. As a result, practitioners have developed a variety of tools and techniques (e.g., a simplified geochemical point scoring system; radial diagrams (Carey et al. 2003)) to assist in interpretation.

\subsubsection{Third Line of Evidence}

The third line of evidence consists of other information from field or microcosm studies (Wilson et al. 1996) which directly demonstrates or quantifies the occurrence of a particular natural attenuation process. In some cases, site-specific confirmation and direct measurement of processes and rates using microcosms or equivalent methods is necessary. This is normally reserved for large or complex sites where contaminant and geochemical data do not provide sufficient basis for adopting natural attenuation. Recent studies indicate promise in field-scale testing and in confirming the presence and rates of specific degradation mechanisms using advanced bioassessment tools such as deoxyribonucleic acid (DNA) and ribonucleic acid (RNA) profiles and messenger (m)RNA levels. Development of low-cost site-specific direct measures of degradation is potentially revolutionary and may influence multiple lines of evidence in the future.

\subsection{Putting it Together}

Throughout characterization and monitoring, models are used to integrate and interpret data. These models range from simple engineering calculations (Newell et al. 2002) to analytical solutions such as BIOCHLOR (Aziz et al. 1999) or numerical models such as RT3D (Clement 1997). Such models provide an integrated platform for analyzing site data and to confirm or quantify attenuation. Models are likely to become even more important to future developments if the of mass balance approach is widely adopted. 
WSRC-STI-2006-00084 Rev. 1

August 1, 2006

Page 9 of 53

\subsection{Enhancing the Original Approach}

In a parallel document Looney et al. (2006) describe the potential application of mass balance to MNA. In addition, they compare and contrast two different approaches, empirical and deterministic, to long-term site management. Their discussions are summarized below.

The original protocol can be enhanced in two principal ways: (1) explicitly applying mass balance as the central concept for characterization and monitoring (Looney et al. 2006); and (2) incorporating new methods and techniques into the lines-of-evidence approach. Applying mass balance means comparing contaminant loading against the attenuation, that results from the natural capacity, to estimate whether a contaminant plume is expanding, stable or shrinking.

The lines-of-evidence approach is primarily an empirical approach to mass balance. At the extreme, the empirical approach depends entirely on measured observations. It works well for sites where the goal is to observe past and present behavior of the system and there is no disturbance to the natural system.

For sites where there is active disturbance of the natural system, however, a deterministic approach to mass balance is needed. A deterministic approach relies on the use of process models to extrapolate in time and/or space beyond actual data. In addition a deterministic can be used to predict future system behavior and performance of MNA. Empirical results are still necessary to calibrate and/or validate the deterministic results.

\subsection{Explicit Use of Mass Balance}

Remediation alternatives that rely on natural mechanisms ultimately depend on the attenuation capacity of the system; the sum of the various mechanisms must be sufficient to attenuate the contaminants and protect potential receptors (Figure 5.1). The concept of a mass balance between the loading and attenuation of contaminants in a groundwater system is a powerful framework to conceptualize and quantify the relative stability of a contaminant plume (Looney et al. 2006).

In most systems, a contaminant is present in source areas in a variety of forms that include nonaqueous phase liquids, chemically sorbed mass, or contaminant mass that has diffused into pores in low-permeability clays, shales, or other rocks. Regardless of how it is stored, the sum of the processes contributing dissolved contaminant mass to water (NAPL dissolution, desorption, diffusion) represents the contaminant-loading component of the mass balance. The sum of the systems natural ability to remove or disperse the contaminants represents the natural attenuation capacity component of the mass balance (Figure 5.1).

The goal of characterization is to provide evidence whether or not attenuation capacity is sufficient and sustainable to offset loading. The goal of monitoring is to verify that attenuation capacity is maintained over time and as conditions vary or remediation goals are met. For mass balance to be useful in engineering practice, however, it is necessary to quantify it in practical ways that facilitate overall site remediation and which are consistent with existing regulatory 


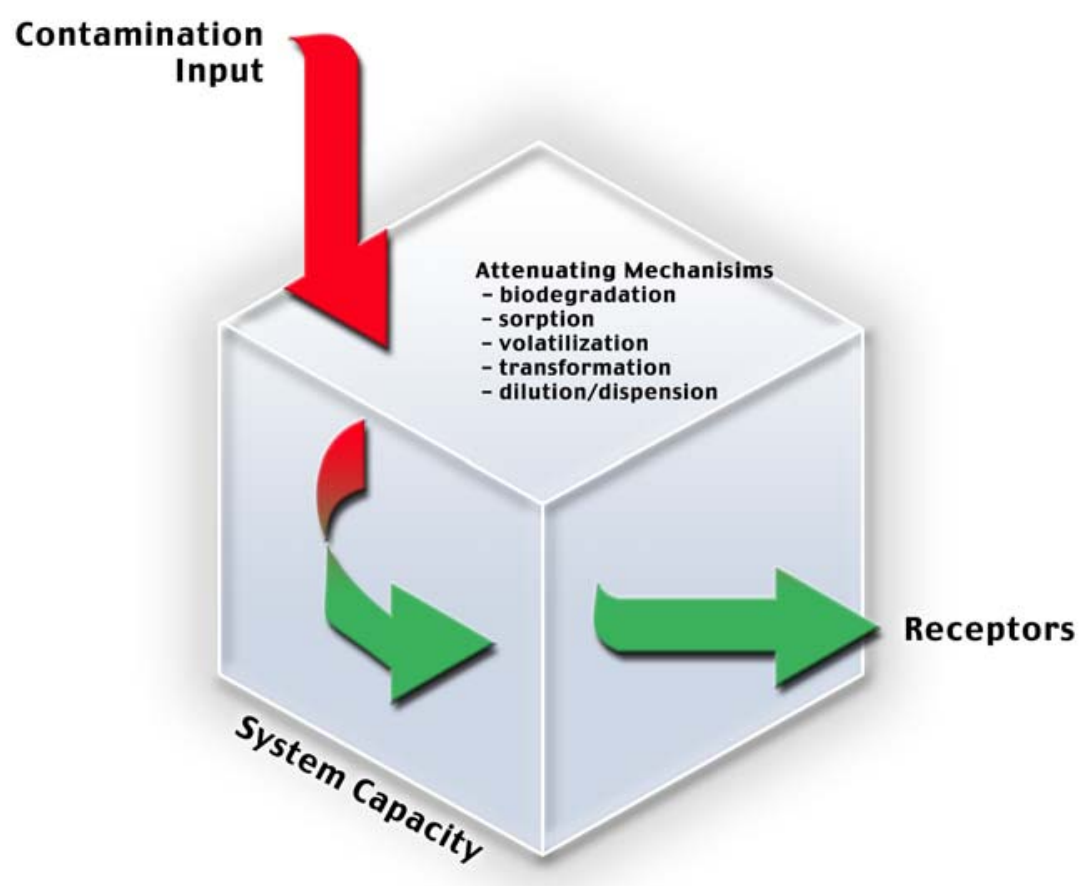

Figure 5.1. Mass Balance Between Contaminant Loading and System Capacity

guidance. Characterization and monitoring of a site will therefore be guided by the approach; either an empirical or deterministic approach or a combination of the two.

\subsection{Empirical/Deterministic Approach}

The mass balance of the system can be either observed (empirical approach), or formulated in terms of the physical, chemical, and biochemical processes and solving equations for each contaminant (deterministic approach). Although, for purposes of description the two approaches are presented here as end members, they will normally be applied in combination.

The empirical approach is most useful in determining the overall natural attenuation capacity of a system at a specific time. As long as the distribution of monitoring wells is sufficient to accurately characterize the plume and there is a good understanding of the transport aspects of the plume, this approach involves using the fewest number of assumptions to estimate the natural attenuation capacity of a system. The first and second lines of evidence are based on empirical data. Decisions are based on the trends in observations. This straightforward approach can provide solid evidence on which to base a decision. But, while the empirical approach is useful for documenting the current conditions, it is less useful for making predictions concerning future conditions. This is particularly true at sites under active remediation, where factors that control the fate of contaminants are being changed. Observations at such sites are unlikely to provide 
reliable predictions. Suitability of the site as a candidate for MNA and decisions on MNA use should not be based solely on data collected during active remediation.

To estimate future behavior, the time-dependent mass balance equations of the deterministic approach are necessary. Mass balance equations for each contaminant need to be formulated in terms of the physical, chemical, and biochemical processes. This approach to mass balance assumes that the fundamental processes affecting natural attenuation are the same from site to site. In addition, the deterministic approach can be used to evaluate how uncertainties in groundwater flow rates, biodegradation rates, and contaminant sorption/desorption may affect behavior of a system. For sites where the delineation of source areas and plumes is less well established, this approach can guide future monitoring and remediation activities (Chapelle and Bradley 1999 (Case Study 5.1)).

During a cleanup investigation, the site manager typically uses simple and straightforward deductive modeling (e.g., BIOCHLOR) and inductive (e.g., evaluation of monitoring data) thinking to understand and predict behavior. Truex et al. (2002) provide an example of how a numerical model can be used to effectively apply MNA where the traditional lines of evidence may not directly apply. The site described by Truex et al. (2002) was in transition from an active remedy (pump-and-treat) to MNA. The model predicted that contaminant concentrations would temporarily increase as a result of rebound from turning the system off, but then stabilize before reaching receptors. (Case Study 5.2)

\subsection{Deterministic Approach and Enhanced Attenuation}

Both simple and complex monitoring strategies have a place in EA. The deterministic approach requires more intensive characterization and monitoring; however, it yields specific information about individual attenuation processes and their impact on the system. The approach allows the effectiveness of MNA to be assessed. It can also enable evaluation of processes that could be enhanced. The EA concept is developed in more detail in a companion document (Early et al. 2006). Essentially, EA asks the question: Is it possible to manipulate natural attenuation processes so they operate more effectively and, thereby, result in an increased reduction in mass flux of contaminants sufficient to meet regulatory release requirements?

Examples of enhancements include the following:

- Adding an amendment that stimulates a natural bacteria to increase the rate of degradation or the overall extent of degradation over that which occurs without the amendment

- Augmenting the natural consortia of microbes with additional species that will increase the overall degradation of contaminants

- Construction of an alternative cap/cover that will result in a decrease in the overall loading of contaminants

A deterministic approach is particularly important to evaluating these enhancements because the impact of an enhancement may not be manifested for some time - perhaps years as in the case of 
plant-based enhancements where it may take several years for trees to mature before the system can respond to them and effects can be measured (Early et al. 2006). Likewise, if the mass balance within a plume being treated by EA changes (as determined by mass flux measurements), the reason may not be apparent. Under these circumstances, deterministic reassessing of individual attenuation processes and the effectiveness of specific enhancements may be helpful.

In practice, the most reliable methodology for assessing natural attenuation capacity and the future behavior of a contaminated site is to employ a combination of the empirical and deterministic approaches. Each method offers unique, but complementary, capabilities with which to assess the effectiveness of enhancements and EA. The empirical approach is particularly useful for assessing the potential role of natural attenuation in overall site remediation at the present time. The deterministic approach is more useful for predicting how a remedial action may affect the behavior of a site, and showing how uncertainties of parameters may affect such estimates (Looney et al. 2006).

\section{Case Study 5.1: Selecting Remediation Goals by Assessing the Natural Attenuation Capacity of Groundwater Systems (Chapelle and Bradley 1999)}

Remediation goals for the source areas of a chlorinated ethane-contaminated groundwater plume were identified by assessing the natural attenuation capacity of the aquifer system. The redox chemistry of the site indicated that sulfate-reducing conditions facilitate the reduction of perchloroethene (PCE) through several breakdown products to vinyl chloride (VC). Further downstream, the redox conditions promote the oxidation of $\mathrm{VC}$ to the final breakdown products, carbon dioxide and chloride. This sequence gives the aquifer a substantial capacity for biodegrading chlorinated ethenes.

The natural attenuation capacity (the slope of the steady-state contaminant concentration profile along a groundwater flow path) is a function of the biodegradation rates, aquifer dispersivity characteristic, and groundwater flow velocity. A boundary-value problem was used to estimate levels to which contaminant concentrations in the source areas must be lowered (by engineered removal) or groundwater flow velocities lowered (by pumping) for the natural attenuation capacity to achieve regulatory limits.

A kinetic assessment of the natural attenuation capacity indicated that concentrations of PCE and TCE must be lowered below $100 \mathrm{ug} / \mathrm{L}$ at least $70 \mathrm{~m}$ from the point of compliance, and that concentrations of DCE and VC must be lowered below $100 \mathrm{ug} / \mathrm{L}$ at least $30 \mathrm{~m}$ from the point of compliance. Because lowering the rate of groundwater flow away from a source area can increase the natural attenuation capacity of a system, remediation goals could be accomplished using conventional pump-and-treat. 
WSRC-STI-2006-00084 Rev. 1

August 1, 2006

Page 13 of 53

\section{Case Study 5.2: Use of the Deterministic Approach for Calculating a Mass Balance in Developing a Site Long-Term Monitoring Plan (Truex et al. 2002)}

Fate and transport modeling can be integrated into both the evaluation and implementation of MNA. Recently, at a site on the National Priorities List, modeling was accepted as a key technical basis supporting EPA approval of MNA as the remedial action for a chlorinated solvent plume. Simulation results provided a prediction of the future plume behavior that will be used to evaluate long-term monitoring data and determine whether attenuation processes continue to occur as expected. A deterministic approach for the MNA evaluation was selected for this site because the groundwater flow rate and direction vary significantly seasonally. Additionally, a groundwater recovery system had operated for approximately 6 years and had perturbed the plume. As such, it would not have been possible to assess MNA with an empirical approach at this site.

A numerical fate and transport model was configured and calibrated to the available data. Model predictions indicated that the plume would stabilize after a period of time and cease migrating further downgradient from the source due to the attenuation capacity within the groundwater system. MNA was selected as the remedy based on these results and a monitoring plan was initiated as part of the MNA remedy to verify that MNA will continue to meet the remediation objectives in the future as expected from the modeling results.

Fate and transport modeling combining attenuation mechanisms and solute transport were used to predict contaminant concentration profiles in the future. The modeling results included concentration profiles as a function of time for each contaminant species in the plume. Because the contaminant source area was hydraulically contained for about 6 years, after groundwater extraction wells were stopped, it was expected that contaminant concentrations would increase downgradient of the source over a period of about 10 years before the plume stabilizes. However, the contaminant concentrations were expected to increase at a rate that is much lower than would occur with no natural attenuation processes. In addition, contaminant concentration profiles were expected to follow a specific pattern based on the dechlorination processes observed in sitespecific microcosm tests. If the actual contaminant plume becomes stable in the future as expected, the concentration profiles of each contaminant species over time should be similar to the profiles predicted by the model. Thus, the long-term monitoring plan for the site uses a comparison of predicted concentration profiles to measured concentration profiles to evaluate the performance of the selected MNA remedy. 
WSRC-STI-2006-00084 Rev. 1

August 1, 2006

Page 14 of 53

\subsection{Developing Techniques and Concepts for Characterization}

The goal of characterization is to provide evidence that the attenuation capacity in the system is sufficient and sustainable and the goal of monitoring is to verify the attenuation capacity is maintained over time and as conditions vary and finally that remediation goals are met.

Using the mass balance concept as a guide, the key parameters to characterize and subsequently monitor, are shown in Table 6.1. As is recognized by practitioners, many of the parameters in Table 6.1 are difficult to directly measure. Biodegradation, for example, is a term that is not currently measured directly; instead parameters such as respiration products, degradation breakdown products and indicators of conditions that support biodegradation are measured that indicate the biodegradation process is active. A technical advance of MNA would therefore be a direct measure of biodegradation. In the proceeding sections we critically explore some new techniques and concepts for characterization and monitoring.

\subsection{Direct Measures}

A major difficulty in measuring natural attenuation lies in its complexity and in the fact that most of the dominant and critical attenuation mechanisms cannot be determined directly. For example, in current practice, there is no direct measure that biodegradation is occurring. Instead, indicators that measure conditions suitable for biodegradation and breakdown products are

\begin{tabular}{l}
\hline A strategy for characterizing \\
and monitoring should be \\
based on cost-effective \\
identification of attenuating \\
mechanisms and verifying, \\
quantifying and tracking the \\
contaminants and attenuation \\
capacity in a system.
\end{tabular}
collected to provide evidence that biodegradation is occurring. Therefore, multiple parameters are needed plus an understanding of their relationships to accurately assess MNA. The intent is to develop a preponderance of evidence to demonstrate biodegradation is occurring. The stakeholder or decision makers determine the amount of evidence needed in order to make a defensible decision. The question then arises, how much evidence is enough? In addition, breakdown pathways for attenuation processes are still not fully understood, which increases the uncertainty. For example, the current concept of measuring the breakdown product ethene is not always a definitive measure of reductive dechlorination because ethene may be, along with other partially dechlorinated hydrocarbons, be removed by anaerobic oxidative processes. Regulators recognize the difficulty of determining biodegradation. Guidance from the State of Minnesota states that the effective characterization of the intrinsic bioremediation of chlorinated compounds requires an understanding of the conditions that favor biotic degradation of that compound and the metabolic intermediates or breakdown products resulting from the degradation of the parent contaminant (Minnesota Pollution Control Agency 1999).

One of the most significant improvements to the process would be the direct measure of contaminant degradation, i.e., measuring directly the presence of the microbes that degrade the contaminants of concern, as well as their activity for breaking down that contaminant. 
Table 6.1. Summary of Important Processes for Mass Balance Calculation

\begin{tabular}{|c|c|c|c|c|c|}
\hline Process & Description & Field Based Characterization & $\begin{array}{l}\text { Characterization/ } \\
\text { Monitoring Phase } \\
\text { Priority to collect }\end{array}$ & $\begin{array}{c}\text { Enhance Attenuation } \\
\text { Potential to } \\
\text { manipulate }\end{array}$ & Quantification \\
\hline Advection & $\begin{array}{l}\text { Movement of solute by bulk } \\
\text { groundwater movement. }\end{array}$ & $\begin{array}{l}\text { Hydraulic conductivity }(\mathbf{K}) \text { - Aquifer } \\
\text { tests; est. based on grain size } \\
\text { Effective Porosity }\left(\mathrm{n}_{\mathrm{e}}\right) \text { - Bulk density } \\
\text { measures in lab; est based on grain size } \\
\text { Gradient }(\mathrm{dH} / \mathrm{dL}) \text { - water-level monitoring } \\
\text { Direct measure; Flow sensors; e.g., } \\
\text { hydrotechnics }\end{array}$ & $\begin{array}{l}\text { Screening } \\
\text { Characterization } \\
\text { Priority - high }\end{array}$ & $\begin{array}{l}\text { High potential to } \\
\text { manipulate }\end{array}$ & $\mathrm{v}_{\mathrm{x}}=-\frac{\mathrm{K}}{\mathrm{n}_{\mathrm{e}}} \frac{\mathrm{dH}}{\mathrm{dL}}$ \\
\hline Dispersion & $\begin{array}{l}\text { Fluid mixing due to groundwater } \\
\text { movement and aquifer heterogeneities. }\end{array}$ & $\begin{array}{l}\text { None; } \\
\text { Estimated from fundamental physics } \\
\text { Estimated from site properties \& modeling }\end{array}$ & $\begin{array}{l}\text { Decision } \\
\text { Characterization } \\
\text { Priority - low, site } \\
\text { specific }\end{array}$ & $\begin{array}{l}\text { Low potential to } \\
\text { manipulate }\end{array}$ & $\begin{array}{l}\text { Estimated by: } \\
\alpha_{\mathrm{x}}=0.83\left(\log _{10} \mathrm{~L}_{\mathrm{P}}\right)^{2.414} \\
\text { or } \\
\qquad \alpha_{\mathrm{x}}=0.1 \mathrm{~L}_{\mathrm{p}}\end{array}$ \\
\hline Diffusion & $\begin{array}{l}\text { Spreading and dilution of contaminant } \\
\text { due to molecular diffusion. }\end{array}$ & $\begin{array}{l}\text { None; } \\
\text { Estimated from fundamental physics } \\
\text { Estimated from site properties \& modeling }\end{array}$ & $\begin{array}{l}\text { Decision } \\
\text { Characterization } \\
\text { Priority - low, site } \\
\text { specific }\end{array}$ & $\begin{array}{l}\text { Low potential to } \\
\text { manipulate }\end{array}$ & $\begin{aligned} F & =-D \frac{d C}{d x} \\
\frac{d C}{d t} & =D \frac{d^{2} C}{d x^{2}}\end{aligned}$ \\
\hline Sorption & $\begin{array}{l}\text { Reaction between aquifer matrix and } \\
\text { solute whereby relatively hydrophobic } \\
\text { organic compounds become sorbed to } \\
\text { organic carbon or clay minerals. }\end{array}$ & $\begin{array}{l}\text { Batch laboratory testing or measure each } \\
\text { parameter in lab (i.e., organic carbon } \\
\text { content }\left(f_{\text {oc }}\right) \text { and clay mineral content, bulk } \\
\text { density }\left(\rho_{b}\right) \text {, specific surface area, and total } \\
\text { porosity }(n) \text { and contaminant properties } \\
\text { (solubility, hydrophobicity, octanol-water } \\
\text { partitioning coefficient). } \\
\text { Push/Pull tests for field scale measures }\end{array}$ & $\begin{array}{l}\text { Screening } \\
\text { Characterization or } \\
\text { Decision } \\
\text { Characterization } \\
\text { Priority - important to } \\
\text { measure particularly in } \\
\text { Decision } \\
\text { Characterization phase }\end{array}$ & $\begin{array}{l}\text { Moderate potential to } \\
\text { manipulate }\end{array}$ & $\begin{array}{c}\mathrm{R}=1+\frac{\rho_{\mathrm{b}} \mathrm{K}_{\mathrm{d}}}{\mathrm{n}} \\
\mathrm{K}_{\mathrm{d}}=\mathrm{f}_{\mathrm{oc}} \cdot \mathrm{k}_{\mathrm{oc}} \\
\mathrm{v}_{\mathrm{c}}=\frac{\mathrm{v}_{\mathrm{x}}}{\mathrm{R}}\end{array}$ \\
\hline Recharge & $\begin{array}{l}\text { Movement of water through vadose } \\
\text { zone into the saturated zone. }\end{array}$ & $\begin{array}{l}\text { Field lysimeters, water flux meters, } \\
\text { geophysics (TDR, neutron), soil moisture } \\
\text { samples, tracers. }\end{array}$ & $\begin{array}{l}\text { Screening } \\
\text { Characterization or } \\
\text { Decision } \\
\text { Characterization }\end{array}$ & $\begin{array}{l}\text { Moderate to high } \\
\text { potential to manipulate }\end{array}$ & Site Specific \\
\hline
\end{tabular}


Table 6.1. Summary of Important Processes for Mass Balance Calculation (continued)

\begin{tabular}{|c|c|c|c|c|c|c|}
\hline Process & Description & Field Based Characterization & $\begin{array}{l}\text { Characterization/ } \\
\text { Monitoring Phase } \\
\text { Priority to collect }\end{array}$ & $\begin{array}{c}\text { Enhance } \\
\text { Attenuation } \\
\text { Potential to } \\
\text { manipulate }\end{array}$ & Quantification & \\
\hline Volatilization & $\begin{array}{l}\text { Volatilization of contaminants } \\
\text { dissolved in groundwater into the } \\
\text { vapor phase (soil gas). }\end{array}$ & $\begin{array}{l}\text { Estimated from literature and } \\
\text { fundamental physics (i.e., partial } \\
\text { pressure) } \\
\text { Soil gas probes }\end{array}$ & $\begin{array}{l}\text { Screening } \\
\text { Characterization or } \\
\text { Decision } \\
\text { Characterization }\end{array}$ & $\begin{array}{l}\text { Low to moderate } \\
\text { potential to } \\
\text { manipulate }\end{array}$ & & \\
\hline Biodegradation & $\begin{array}{l}\text { Microbially mediated oxidation- } \\
\text { reduction reactions that degrade } \\
\text { contaminants. }\end{array}$ & $\begin{array}{l}\text { Indirect measures; daughter products, } \\
\text { nutrients, environmental conditions, } \\
\text { respiration activity and end-products } \\
\text { Direct measures; nucleic acid based } \\
\text { tools }\end{array}$ & $\begin{array}{l}\text { Characterization or } \\
\text { Decision } \\
\text { Characterization }\end{array}$ & $\begin{array}{l}\text { Moderate to high } \\
\text { potential to } \\
\text { manipulate }\end{array}$ & Site Specific & \\
\hline $\begin{array}{l}\text { Abiotic } \\
\text { Degradation }\end{array}$ & $\begin{array}{l}\text { Two Mechanisms: } \\
\text { (1) Chemical transformations that } \\
\text { degrade contaminants without } \\
\text { microbial facilitation; } \\
\text { (a) Hydrolysis } \\
\text { (b) Degradation caused by the } \\
\text { presence of pyrite, } \\
\text { magnetite, green rust, etc. } \\
\text { (2) Biologically Mediated Abiotic } \\
\text { Degradation; } \\
\text { (a) Abiotic degradation caused } \\
\text { by microbial production of } \\
\text { FeS. } \\
\text { Only halogenated compounds are } \\
\text { subject to these mechanisms in the } \\
\text { groundwater environment. }\end{array}$ & Indirect measures & $\begin{array}{l}\text { Characterization or } \\
\text { Decision } \\
\text { Characterization }\end{array}$ & $\begin{array}{l}\text { (1a) and }(1 \mathrm{~b}) \text { low to } \\
\text { moderate potential to } \\
\text { manipulate } \\
\text { ( } 2 \mathrm{a}) \text { moderate } \\
\text { potential to } \\
\text { manipulate (new } \\
\text { technology that } \\
\text { appears very } \\
\text { promising) }\end{array}$ & & 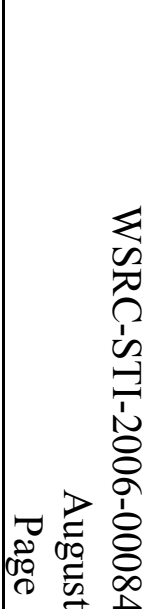 \\
\hline $\begin{array}{l}\text { Partitioning from } \\
\text { NAPL }\end{array}$ & $\begin{array}{l}\text { Partitioning from NAPL into } \\
\text { groundwater. NAPL whether mobile } \\
\text { or residual, tend to act as a continuing } \\
\text { source of groundwater contamination. }\end{array}$ & $\begin{array}{l}\text { Estimated from literature \& } \\
\text { fundamental physics (i.e., solubility, } \\
\text { partial pressure) } \\
\text { Estimated from modeling }\end{array}$ & $\begin{array}{l}\text { Decision } \\
\text { Characterization }\end{array}$ & $\begin{array}{l}\text { Low potential to } \\
\text { manipulate }\end{array}$ & & 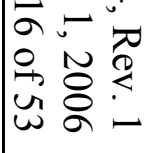 \\
\hline
\end{tabular}




\subsubsection{Direct Measures of Biodegradation}

Direct measurement of key processes and degradation rates would eliminate the question of where biodegradation is actually occurring along the groundwater flow path.

In situ microcosms (ISM) can be used to measure specific degradation activities at locations (Case Study 6.1). Specific concerns about ISM are that they still require an incubation period, and their design and operation may bias the results (i.e., actual rates) or prevent gathering information on the type of activity that could be induced. Recent advances in nucleic acid probes hold tremendous promise to overcome these limitations. The tools can provide direct evidence that (1) the important microbes are present, (2) they are actively degrading (or have the potential to degrade) the compounds of concern, and, ultimately, (3) the in situ biodegradation rate at the time of sampling. The primary limitation of molecular biology tools is in obtaining a representative sample and extraction of genetic material from the sample. However, molecular tools offer the ability to answer key questions about biological attenuation mechanisms (Case Study 6.2). For example:

- Will reductive dechlorination continue to occur down gradient if the plume expands based on the microbial ecology of this down gradient area?

- Is anaerobic-oxidation a viable attenuation mechanism for partially dechlorinated solvents now or in the future based on the microbial ecology in the aquifer?

- If the groundwater plume of cis-1,2-dichloroethene (cDCE) is projected to enter the surface water, will it be degraded because microorganisms that aerobically degrade cDCE are present in the sediment?

\subsubsection{Available Molecular Tools}

Current estimations suggest that $1 \mathrm{~g}$ of soil or sediment contains $10^{10}$ more bacteria than are microscopically detectable, equating to as many as $10^{2}$ to $10^{3}$ distinct species (Torsvik et al. 1990, 1998). To understand this microbial diversity, molecular biological techniques and concepts have been adopted and incorporated into microbiological research. Rather than culturing organisms in the laboratory, signature molecules are extracted directly from an environmental matrix and used to identify, characterize, enumerate, or track specific microorganisms or even entire microbial communities that influence environmental pollutants. These methods can be used to identify organisms and their activities, tease out interactions between populations, as well as monitor community level dynamics spatially and temporally (Gossett 2002). The Strategic Environmental Research and Development Program also recognizes the potential importance of these tools to environmental characterization and monitoring and recently published a strategic plan that identifies research and development needs for some of these molecular tools (SERDP 2005)

The basis of these tools is the deciphering of the complete DNA sequence of an individual microorganism to understand its biology. Deciphering is usually identification of specific genes that regulate the growth and metabolism of an organism. The work conducted to date has 


\section{Case Study 6.1: Assessing Natural Degradation with In Situ Microcosms}

Laboratory microcosms are rarely able to accurately replicate existing in situ conditions, such as oxidation-reduction potential, electron donor/electron acceptor concentrations and fluxes, temperature, microbial populations, and geochemical characteristics. The ability to evaluate bioremediation processes on site and in situ provides another level of insight into the occurrence and rate of natural degradation processes, plus the potential for engineered actions to achieve groundwater restoration. The MICRO-Trac (Modular In-Situ Community Response Outfit) from SiREM (www.siremlab.com) was designed for in situ treatability tests under field conditions. The system is composed of test cassettes that are loaded with materials to simulate natural attenuation, biostimulation with various electron donors, and bioaugmentation with dechlorinating bacterial consortia. The cassettes also contain diffusion samplers and a microbial growth matrix (Figure 1). The cassettes fit inside standard 2-inch monitoring wells. A typical ISM study consists of an untreated control to evaluate natural degradation processes, an electron donor-amended treatment to evaluate effects of biostimulation on solvent degradation, and an electron donor and microbe-amended treatment to evaluate effects of bioaugmentation. Units are typically placed one per well, although multiple units have been deployed successfully in a single well (Figure 2). Units are incubated in situ for 6 to 8 weeks prior to sample recovery.

The MICRO-Trac was applied at Fulmer's Cleaners, Leesburg, Florida to evaluate PCE degradation under conditions that simulated natural attenuation, biostimulation and bioaugmentation with lactate as the

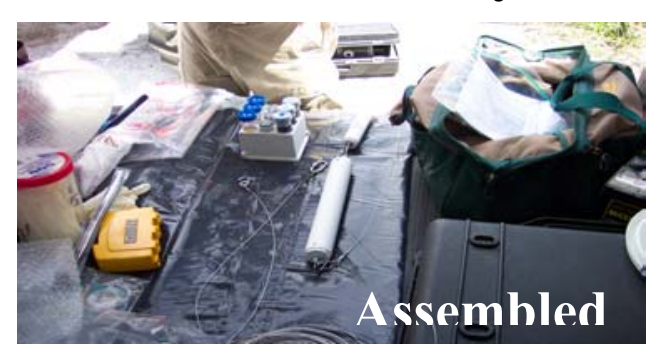
injectate. MICROTrac cassettes were

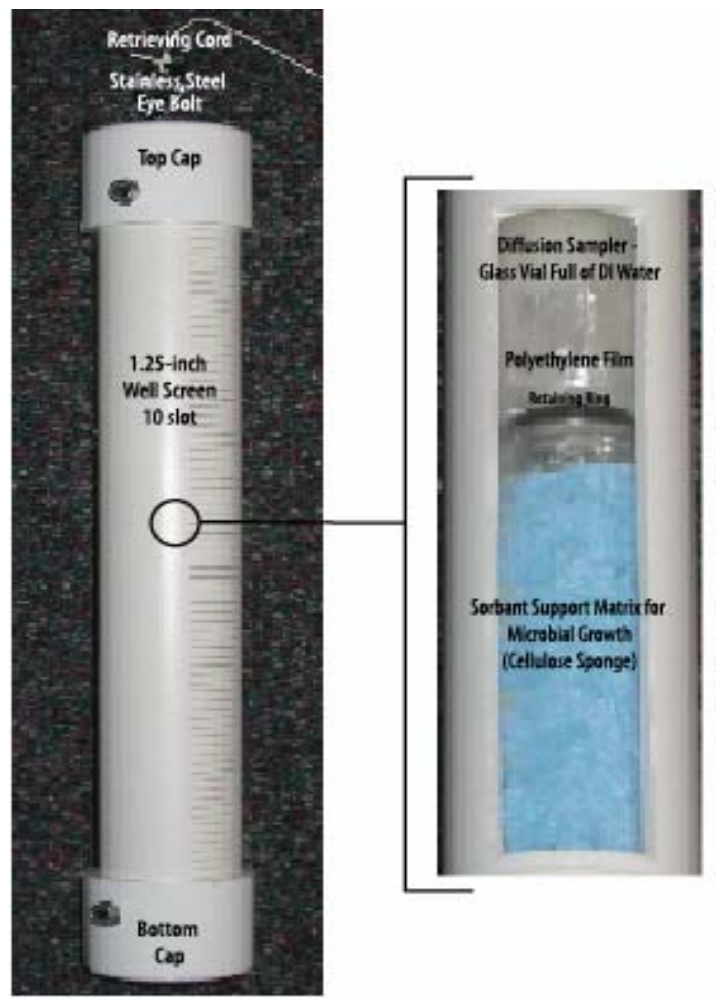

Figure 1. MICRO-Trac suspended in a monitoring well and allowed to react for 8 weeks. Retrieved cassettes were analyzed for PCE, TCE, cis-1,2-DCE, trans-1,2-DCE, VC, ethene, ethane, methane, and Dehalococcoides ethanogenes. Results are summarized below:

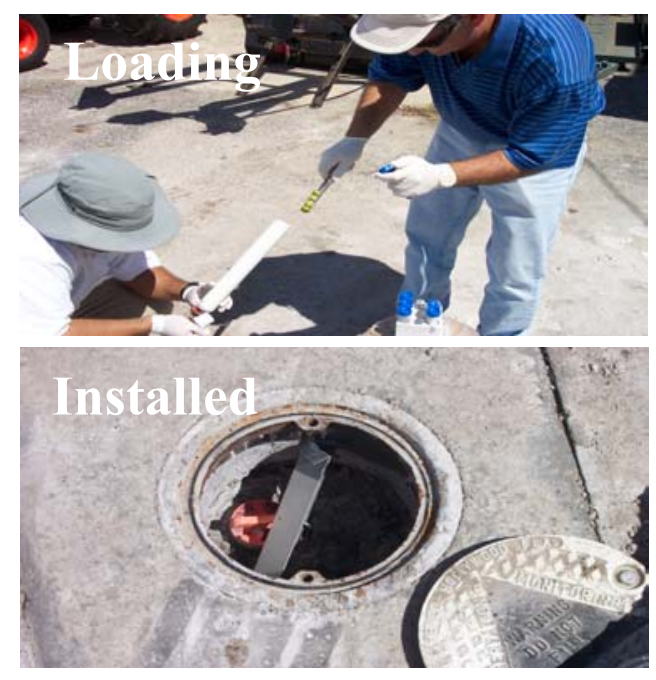

Figure 2. Installing MICRO-Trac

\begin{tabular}{|l|l|l|l|}
\hline \multicolumn{1}{|c|}{ Treatment } & \multicolumn{1}{c|}{ Amendment } & \multicolumn{1}{c|}{ Dehalococcoides } & \multicolumn{1}{c|}{ Observed Products } \\
\hline Control & None & Not detected & TCE, cis-1,2-DCE \\
\hline Biostimulated & Lactate & Not detected & TCE, cis-1,2-DCE \\
\hline Bioaugmented & Lactate KB-1 & Detected & TCE, cis-1,2-DCE, ethene \\
\hline
\end{tabular}

The MICRO-Trac test provided information necessary to assess the potential for PCE to be biodegraded at the site. Results indicated that bioaugmentation should be considered for the complete dechlorination of PCE and that simple biostimulation with lactate would only support partial PCE dechlorination. The entire testing and analytical program was completed in less than 12 weeks for a cost of $\$ 2,200$ plus the labor to install the cassettes in the monitoring well and retrieve them.

As a tool to support MNA and EA, the MICRO-Trac provides chemical data to evaluate attenuation processes, as well as a method to evaluate potential EA technologies and their impact on the system remediation. An important constraint is the well in which this tool is placed must be screened in the contaminant plume or the down-gradient flow path of the contaminant plume. 


\section{Case Study 6.2: Development of Molecular Tools for Environmental Work}

The application of the Natural Attenuation remedy can benefit from rapid advances in protein-based assays and other molecular techniques. These techniques have the potential to improve estimates of natural attenuation rates and the ability to isolate genes responsible for biodegradation without the need for culturing bacterial species (Reiss et al. 2004). Degradation rate is a key variable in assessing the viability of MNA at a particular site. However, current MNA protocols rely on estimating degradation rates by assessing the distribution of geochemical parameters. A direct measure of this key process would decrease the large uncertainty of estimating this parameter (Major et al. 2004).

Most of the molecular tools have been developed in the medical community, and application of these tools to environmental issues is an emerging research area. Initial efforts include the development of a rapid assay to monitor 1,2-dichloroethane biodegradation with the goal to isolate the enzymes responsible for biodegradation at geographically separates sites (Reiss et al. 2004). The bacteria Dehalococcoides is reported to dechlorinate chlorinated ethylenes to harmless by-products. Lu et al. (2004) are looking for the presence or absence of Dehalococcoides DNA in water using a polymerase chain reaction with DNA primers specific for Dehalococcoides. This technique could result in a useful screening criterion to identify sites where monitored natural attenuation may be useful. This research area is in its formative stage and significant development in this area is anticipated.

created a large database of known genes that can be compared to newly identified sequenced genes. Metagenomics, an even newer science, goes a step further by sequencing DNA taken directly from an environment to find out what kinds of microorganisms are present, what metabolic capacity they possess, what they are doing, and how they interact with each other and their physical and chemical surroundings. Through extracting all the DNA from an environmental sample, and using sophisticated computational models, we can understand and assess the function of individual microorganisms, the metabolic potential that could be expressed, and the contribution of the entire community that is being expressed to the degradation of chemicals. These methods can also identify key but previously unknown microorganisms and metabolic potentials.

Direct detection of microbial activity will rely on the recovery and characterization of nucleic acids, DNA and RNA, to identify, characterize, enumerate, or track microbial components and activities. The biodegradation potential (i.e., the current or future metabolic potential that can be expressed) would be assessed by extracting and analyzing DNA. DNA contains the genetic codes for various biomolecules involved in cell metabolism, including enzymes that degrade anthropogenic chemicals. The metabolic activity that is currently occurring would be assessed by the extraction and analysis of mRNA. mRNA is involved in the translation of the genes into functional enzymes and proteins; therefore, measurement of mRNA is useful to determine the expression of key genes. 
There are two major molecular approaches to detect the presence of specific microorganisms and their activity: isolation and amplification of specific (universal or functional) nucleic acid sequences, and use of hybridization platforms that contain the entire genome of an organism or a community of microorganisms to allow simultaneous evaluation of thousands of genes. Each of these approaches is summarized below.

Detection of Specific Nucleic Acid Sequences. There are protocols in the literature for the extraction of DNA, RNA, and, more recently, simultaneous extraction of both DNA and RNA fractions (Hurt et al. 2001).

Whether the target sequence is DNA or RNA, the methods require amplification and separation. The polymerase chain reaction (PCR) is generally used to exponentially amplify and isolate the targeted gene (universal or functional) from total genomic DNA extracted from an environmental sample. There are three phases for each PCR amplification cycle of DNA: (1) denaturation: DNA is incubated at high temperature to thermally separate the DNA double helix into individual strands; (2) annealing: the incubation temperature is lowered to allow PCR primers to specifically bind to the target gene; and (3) extension: the enzyme DNA polymerase extends from each PCR primer (that recognizes the beginning and end of the target sequence) to make a complete copy of the targeted gene sequence using the DNA as a template. This cycle is repeated (typically 30 times) to create a pool of PCR product that can be resolved by a variety of methods. For example, the product is placed on a gel that is subjected to an electrical field. The PCR product will migrate to a specific location within the gel that corresponds to its size, and is visualized by exposure to UV light.

The quantification of PCR products (e.g, the number of gene copies in the sample) achieved through the Quantitative Polymerase Chain Reaction (qPCR which has become common practice in medical research or clinical settings for quantification of viral loads or gene expression studies from tissue samples. Theoretically, there is a fundamentally quantitative relationship between a starting template concentration and amplified product formation. Simply, qPCR) provides real-time detection of PCR products as they accumulate. There are 3 different detection platforms (DNA double strand binding dye, SYBR ${ }^{\circledR}$ green, fluorescent hybridization probes, TaqMan ${ }^{\circledR}$ and Molecular Beacons), but all are basically identical in principle. In parallel to an experimental PCR reaction, a positive control of known starting DNA template concentration is amplified under a set of established conditions. PCR product formation in the control sample is plotted against thermal cycle number and this relationship is used to infer a starting template concentration in the experimental reaction. The primary assumption of this method is that the experimental sample behaves identically to the control sample. Unfortunately, it is widely acknowledged that this assumption does not hold true, especially for environmental applications. Nonetheless, qPCR assays have been developed and utilized for the quantification of Dehalococcoides sp. 16S rDNA and functional gene (e.g., vinyl chloride reductase) sequences.

Set-up for cPCR requires up-front instrumentation investments in a thermal cycler, computer, optics for fluorescence excitation (lasers or broad spectrum excitation source), filters for emission detection, and data acquisition / analysis software. 
DNA Hybridization Platforms. Various DNA and RNA hybridization platforms have been developed and used for sensitive detection of microorganisms in samples. One benefit of this approach is that it can provide quantitative information regarding the abundance of a gene or organism in the original environmental sample. Generally, the platforms contain spots of the whole or part of the DNA that has been extracted from a single or multiple species, or the entire microbial community. Known diagnostic sequences of DNA or RNA are labeled and allowed to find their complementary match and hybridized to the spots on the template. Incubated under stringent conditions, with internal standards, the amount of probe found in each dot provides a quantitative measure of an organism's or specific gene's abundance in the original environmental sample. There are a variety of hybridization supports (membranes, glass slides, gel pads) and detection systems (radiolabels, colorimetric, fluorescence) available.

The latest development is the use of DNA microarrays, which have revolutionized our ability to simultaneously monitor the expression of many genes. In essence, microarrays are miniaturized hybridization platforms that allow a single, or even multiple, environmental samples to be interrogated by 50,000 (standard array platform) or up to 500,000 (high-density array platform) oligonucleotide (DNA fragments) probes simultaneously. This capability allows researchers to take full advantage of DNA sequence databases (RDP and/or NCBI) for comprehensive taxonomic, phylogenetic, and functional analysis of environmental samples. Generally, a DNA microarray is a glass microscope slide onto which many thousands of DNA samples have been spotted in a grid (Schena et al. 1995). DNA or mRNA is extracted from cells, labeled with specific fluorescent molecules, and hybridized to the spotted DNA on the glass slide. The resulting image of fluorescent spots is visualized and digitized for quantitative analysis. Depending on the biological question to be addressed, the array can comprise individual genes from an entire genome, a specific subset of genes, or a combination of genes from different microorganisms. RNA from cells grown under different conditions can be used in comparative or differential screening, to identify genes specifically up- or down-regulated by environmental cues. This is particularly important to understand how environmental factors (e.g., cocontaminants, $\mathrm{pH}$ ) turn on or off genes that code for degrading enzymes and the syntropic interaction between species. This technology also has a superior ability to identify unique genes, new bacteria, and community structure. Methods for using DNA microarrays for the quantitative detection of microbial genes and gene expression in the environment are currently under development (Cho and Tiedje 2002; Wu et al. 2001; Dennis et al. 2003) with good success. Challenges remain in the area of method detection limit, normalization, and environmental sample preparation.

\subsubsection{Direct Measures of Flux}

Many remedial technologies, including MNA, are more sensitive to mass flux (or mass loading) than concentration. Integrated mass flux (iMF) is the amount (mass) of solute flowing through a given cross-sectional area of an aquifer over a specified period of time and is the product of groundwater discharge rate and solute concentration. Integrated mass flux is important to consider as part of using the mass balance approach of plume analysis. One application of integrated mass flux measurements is to quantify the contaminant mass loading to the plume from the source area. In this situation, the direct measurement of flux can assist in subsequent analysis of the down-gradient plume using either the empirical or deterministic approaches discussed in Section 5.0. Integrated mass flux measurements can also support empirical analysis 
of a plume under specific conditions as a means to evaluate the attenuation capacity for selected portions of the plume.

One difficulty is measuring the flux or discharge term. The current approach is to estimate the mass of solute flowing across two cross-sectional areas. The basis of this approach is the law of continuity of groundwater flow (i.e., flow in equals flow out). The iMF of a solute across two separate plume transects oriented perpendicular to the direction of solute transport and intersecting the entire plume, must be equal unless there is removal of solute through attenuation. For this approach to be accurate, however, the plume must be at steady state (i.e., the concentrations at the down-gradient edge are not changing and the plume is not expanding or shrinking) and the aquifer geometry and groundwater flow conditions are known well enough to capture the entire plume.

The largest source of error in current methods of measuring flux is associated with aquifer heterogeneity and the subjective process of determining solute distribution. Current flux measurement techniques rely on multiple point-measurements from monitoring wells and subsequent interpolation, which potentially creates error. Increasing the density of monitoring points reduces error but can be expensive. Moreover, Guilbeault et al. (2005) showed that even in relatively homogenous aquifers three quarters of the mass discharge occurs in only $5 \%$ to $10 \%$ of the plume cross-sectional area. Such extreme spatial variability of the mass discharge highlights the difficulty and uncertainty associated with extrapolating from point measurements.

It will be important to measure and quantify the assumptions that go into the mass flux term as well as uncertainty in the measurements. More direct, or spatially integrated techniques to improve the mass flux measurements represent a critical research and development need.

Several ongoing research projects are aimed at evaluating uncertainties in mass flux measurements. For example, the Strategic Environmental Research and Development Program (SERDP) supports Wood (DOD 2004) to evaluate mass flux measurements and uncertainty analysis that will assess both the sources and magnitude of uncertainties. In addition, K. Hatfield and M. Annable of the University of Florida are funded by this DOE alternative project to explore flux measurement uncertainties in the field at the Savannah River Site. Assessment methods for uncertainties in mass flux measurements for specific methods are not yet available ${ }^{1}$ but are a topic of current research.

\subsection{Current Methods for Estimating Contaminant Flux}

Methods for estimating contaminant flux include the use of hydraulic parameters and averaged concentrations from traditional monitoring wells, the use of flux meters, total plume capture by a well, integrated pumping tests (steady- and unsteady-state using single and multiple wells), and recirculation zones. Four methods proposed for measuring mass flux are undergoing testing at the present time. These methods have been described in detail (ITRC 2004):

- Continuous extraction from well transects

\footnotetext{
${ }^{1}$ Personal communication from Hatfield and Wood.
} 
- Integrated pump tests

- Multi-level samples

- Passive borehole flux meters

Sources of uncertainty in these methods include:

- Errors associated with sample collection, processing, and analysis

- Heterogeneities associated with the flow system and pathways of contaminant transport that result in the extreme spatial variability of mass distributions

In general, the more data used in vertically and horizontally defining the site, the more accurate the mass flux calculations will be. However, Guilbeault et al. (2005) showed that volatile organic compound (VOC) concentrations vary as much as 4 orders of magnitude across $30-\mathrm{cm}$ vertical intervals at some locations requiring sample spacing of no larger than 15 to $30 \mathrm{~cm}$ vertically near the source. Herein lies the current problem in using point measurements: what is enough data and how much uncertainty can be tolerated with the data

The challenge is that mass flux is very difficult to measure, which results in the current reliance on point source measurements. A significant technical advance would be to develop methods to more directly measure flux or contaminant discharge. when converted in the mass flux estimates? New characterization and monitoring methods are needed to measure and monitor mass flux.

Acceptance of new approaches will require their proven ability to measure flux, evaluate the uncertainties associated with those measurements, and establish that reliable precision in assessing mass balance can be attained. From a practical standpoint, the approaches must also be cost-effective.

A potential solution may lie in spatially integrated measurements, i.e., measuring contaminant concentrations in an area or volume rather than a number of points. Possible solutions may use geophysical methods to interrogate a subsurface area (see Section 7.5.1). These subsurface areas can rely on natural properties or altered properties that accentuate the measurements. These properties could be related to a direct measure of contaminant concentrations or inferred from changes in the baseline conditions. Research into these and other ideas is warranted.

Some currently available or in-development techniques to measure flux are described in the following paragraphs.

Benthic Flux Sampling Device. The benthic flux-sampling device (BFSD) has been tested and certified by the EPA to measure the contaminant flux in coastal marine sediments affected by tides. The BFSD is an automated, in situ water-sampling device. It collects and filters discrete water samples over a period of up to four days. The samples are preserved and delivered to an analytical laboratory for analysis. The technology has been used at several Department of Defense sites. Additional information can be found at http://www.calepa.ca.gov/calcert/CertifiedTech/BenthFlu. 
UFL Passive Flux Indicator. The University of Florida's passive flux indicator is a selfcontained permeable device inserted into a well or boring that acts as an integrating sampler. Groundwater flows through it and is not retained. The interior of the device is a matrix of hydrophobic and hydrophilic permeable sorbents that retain dissolved organic and inorganic contaminants present in fluid intercepted by the unit. The sorbent matrix is also impregnated with known amounts of water-soluble resident tracers (typically benzoate), which are leached from the sorbent at rates proportional to the fluid flux. Following exposure to groundwater flow for a period ranging from days to months, the passive flux indicator is removed from the monitoring well and the sorbent extracted to quantify the masses of contaminants intercepted and residual masses of resident tracers. The contaminant masses are used to calculate time-averaged contaminant mass fluxes; residual resident tracer masses are used to calculate time-averaged groundwater flux. The passive-flux indicator is being validated through Environmental Security Technology Verification Program (ESTCP) demonstrations at three Department of Defense sites (see http://www.estcp.org/projects/cleanup/200114o.cfm), and is being demonstrated as part of the Monitored Natural Attenuation and Enhanced Attenuation for Chlorinated Solvents Technology Alternative Project supported by DOE.

Integrated Pumping Test. The University of Tübingen has developed a method to estimate mass flux using a well transect. The integrated-pumping test has two stages. In the first stage, each monitoring well in the transect is pumped at a constant rate and the time-varying concentration of the contaminant of interest is recorded. In the second stage, the concentration versus time data for all of the wells are combined using a numerical inversion technique to estimate the mass flux of contaminant across the transect. Unlike the passive flux meter, it allows the maximum and average concentrations over the transect to be estimated. As an active method, the integratedpumping test overcomes localized issues (e.g., borehole damage) that interfere with passive methods and can obtain measurements over a length greater than the well diameter. On the other hand, water pumped from the wells must be disposed of, perhaps as hazardous waste, and multiple chemical analyses are required. This method has been tested at several European sites. Results have been published since 1998.

\subsection{Direct Measure of Advective Flow}

Many, if not most, groundwater systems are made up of permeable media capable of moving dissolved chemicals by advection at rates significantly faster than occurs by dispersion. Thus, two critical components to calculate mass flux are advective flow and dissolved concentration. Dissolved concentration can be measured with some degree of confidence but estimates of advective flow based on conventional methods often have large errors because they are calculated using uncertain parameters. More direct measures of advective flow could reduce uncertainties associated with estimates of mass loading and attenuation capacity. Unfortunately, such direct measures, such as those provided by the passive flux indicator (ESTCP 2004; Hatfield et al. 2004), are still in various stages of development and testing. Thus, making it necessary to rely on greater use of existing technologies that at least provide more direct measures of Darcy velocity than is otherwise used to calculate advective mass flux. 
Four technologies for directly measuring groundwater velocity have been developed. One produces a Darcy velocity that is associated with the passive flux meter for directly measuring dissolved constituent mass flux (ESTCP 2004; Hatfield et al. 2004) that is undergoing testing. This method relies on measurements made inside a sensor that is suspended inside a well casing. Two other methods based on equipment installed in a cased borehole; the K-V Geo Flowmeter (Kerfoot and Massard 1985; Kerfoot 1988) and the colloidal borescope (Kearl and Case 1992; Kearl et al. 1993), are designed to measure Darcy velocity and pore-water velocity, respectively. Because all three above-mentioned techniques depend on the placement of instruments in a well casing, they are affected by (1) materials used to backfill the borehole annulus surrounding the casing; (2) convergence of flow paths near the inflow portion of the groundwater casing or flow divergence in the outflow portion; and (3) screen blockage, fouling or simply open area limitations due to the use of perforated rather than wire- wound screen. Any such methods require careful flow-net construction to be meaningful. Partly because of these factors, the colloidal borescope shows a tendency to overestimate pore-water velocity by factors as large as 3 or greater. When using the colloidal borescope, Darcy velocity must be estimated by multiplying the measured pore-water velocity by an estimated local effective porosity for the aquifer. An apparent limitation of methods that rely on in-casing instruments or sensors is that the velocities estimated are strictly horizontal and vertical components of flow are not captured.

A fourth documented technique for directly measuring groundwater velocity relies on the in situ permeable flow sensor (Ballard 1996), as described in Case Study 6.3. This instrument differs from other flow measurement technologies in that it is buried in direct contact with the materials in which the flow is to be measured rather than being suspended in a well bore. In addition, it is designed to measure all three components of the three-dimensional Darcy velocity vector. Although in some cases the vertical flow can be amplified because of the backfilled borehole, in general it addresses the issues associated with the probes in the boreholes and is a more direct measure of advective flow than can be estimated from the gradient and hydraulic conductivity measurements. 


\section{Case Study 6.3: Directly Measuring Groundwater Flow}

The In Situ Permeable Flow (ISPF) Sensor developed by Sandy Ballard at Sandia National Laboratories (Ballard 1996) uses thermal perturbation to continuously measure the 3-D vector of groundwater velocity. The probe, consisting of a heating element and temperature sensors, is placed in the subsurface in direct contact with the formation of interest, as shown in the cartoon below.

The ISPF was used to evaluate the hydrologic impact of a sinkhole that had formed over the edge of a former salt mine at a petroleum storage facility in Louisiana (Ballard 1996). At issue was the structural stability of the oil storage facility. Flow through the sinkhole was believed to have both horizontal and vertical flow components. The ISPF was installed in a sandy zone below the sinkhole and continuous measurements were taken for 17 days. The temperature measurements as well as physical downward displacement of the probe indicated that flow was dominantly vertical. The groundwater velocity and direction information caused the responsible parties to remove the oil and abandon this facility.

A permanent ISPF facility could be used as part of a long-term performance monitoring system. The ISPF can be used during natural (non-remediated) or disturbed (active treatments are ongoing) settings. One drawback is that this is a point measurement.

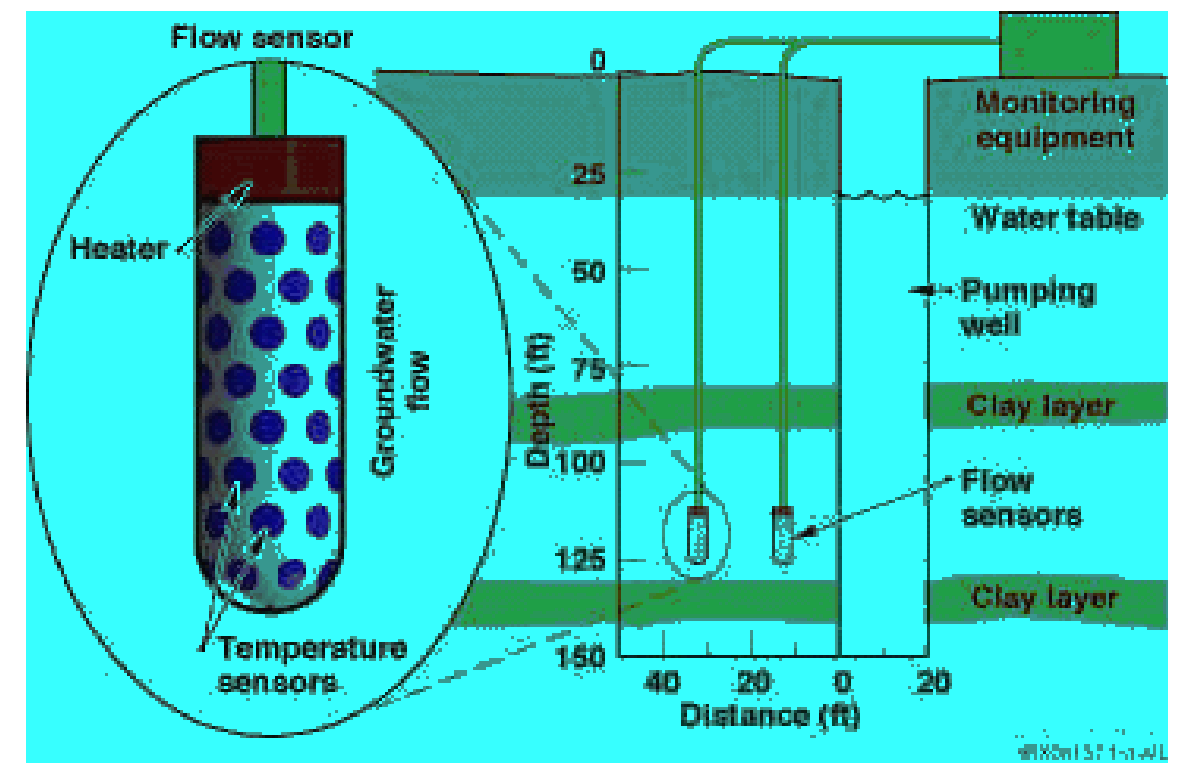

Illustration of ISPF sensor and implacement. 


\subsection{Developing Techniques and Concepts for Monitoring}

The goal of monitoring is to verify that the attenuation capacity is maintained over time and as conditions vary or remediation goals are met. As outlined in Section 3.0 there are two distinct phases of monitoring; process monitoring where the remedy is verified and performance or longterm monitoring where the goal is to ensure the remedy is sustained. Because the goals are different for each of the monitoring phases, so are the approaches.

Verification of the remedy during the process-monitoring phase will logically be a continuation of some of the characterization approaches. In particular, attenuation mechanisms and rates will continue to be measured. Commonly the array of wells used during characterization by default becomes the long-term monitoring network. The generally recognized dilemma with this occurrence is that the effort and cost to monitor over the long-term can be prohibitively expensive. Characterization-well networks should be eventually replaced by monitoring configurations that do not depend on well networks at all. Advances in performance monitoring are needed to promote the use of MNA, particularly at sites with relatively long remediation times. This section will focus on alternative approaches to performance monitoring and will highlight methods to transition from characterization networks to long-term performance monitoring.

This section addresses: 1) methods to transition from process to performance monitoring 2) concepts to promote performance monitoring and 3) examples of alternative monitoring networks.

\subsection{Overall Approach}

Emphasis during the monitoring phases is fundamentally different from the characterization phase, which was focused on collecting as much information as possible so that the subsurface could be adequately described and attenuation mechanisms identified and quantified. During the characterization phase emphasis was given to relatively rapid direct measurements of the phenomena (see Section 6.0). Long-term system performance monitoring, in contrast, may be required for tens to possibly hundreds of years. Therefore, long-term monitoring must as efficient as possible.

Current approaches to long term monitoring focus on gradually reducing the number of samples and sampling locations through optimization of well networks, data quality objective approaches, combining contiguous waste sites, and automated systems. For long-term monitoring, the EPA (1999) document establishes a review process used to adjust data collection over time in order to optimize or streamline data collection. Similarly, the State of Minnesota guidance document recommends that long-term monitoring strategy include a reduction in sampling frequency. Other recent work on long-term monitoring also focused on optimization techniques (Minsker 2003; Chan Hilton and Li 2005, and Herrera and Pinder 2005). While these approaches are merited, given the long time periods some sites may be monitored, techniques based on well networks may not be appropriate in the long run. At some point, enough information will have 
been gathered to verify the remedy and establish the baseline for system performance. Then the monitoring focus should transition to an approach based on detecting change outside the expected range. When long-term monitoring is directed toward this objective, opportunities for innovation arise. For example, an ecosystem approach might monitor departures of large-scale parameters (ground cover, vegetation type, etc.) from a baseline. These larger-scale monitoring techniques may be most efficient for long-term monitoring. While research is needed to fully develop this concept, several examples in various stages of development will be described in the following sections. In addition, techniques to transition from process monitoring to performance monitoring are discussed. Strategies and techniques that go beyond the optimization of the characterization well network are needed, particularly for sites with long remediation time frames.

\subsection{Conceptual Development of Performance Monitoring}

In developing new approaches to performance monitoring the objectives and desired attributes of a performance monitoring (long-term) monitoring network need to be identified and considered. The objectives according to the 1999 EPA guidance, Performance Monitoring of MNA Remedies for VOCs in Ground Water, are that MNA monitoring be able to 1) demonstrate that natural attenuation is occurring according to expectations (measuring within a predicted range) and verify attainment of remediation objectives. The desired attributes are identified in Table 7.1.

\section{Table 7.1 Attributes of Performance Monitoring}

- Measure change from baseline (predicted range)

- Utilize indicator parameters that represent a set of properties (e.g., resistivity)

- Utilize spatially integrated measures (e.g. flux)

- Measure ecological health

- Low maintenance

- Low cost

- Robust

- Passive

- Utilize leading (failure) indicators

- Flexible to incorporate new tools

Adherence to the attributes in Table 7.1 should promote non-traditional monitoring configurations that efficiently meet the objectives.

Some of the most innovative solutions to problems come at the confluence of disciplines. Solutions from one discipline can be adapted to others. The same holds true with environmental cleanup. For example, long-term monitoring strategies and approaches used for landfill caps and covers may be relevant for MNA sites. Significant advances have been made and some innovative methods for monitoring containment liners and covers have been developed (EPA 2004c). There is synergy with this work and system performance monitoring of MNA. Other fields that may also be applicable to MNA are ecological monitoring, climate change, and 
archeology. A good start to develop and optimize long-term monitoring to support a systems performance approach for MNA is to look at these other disciplines for ideas.

The key to long-term monitoring is to monitor for change that is outside the predicted range.
Performance (long-term) monitoring could be more efficient and potentially more effective using a natural systems approach in which larger scale perturbations are monitored and compared to a baseline. A change from the predicted range

may warrant further investigation or actions. These new strategies and techniques must be sufficiently developed to make them acceptable to regulators and stakeholders. Examples of new approaches that are presented in the following sections can serve as technical targets for the development of a systems-performance-based approach to long-term monitoring.

\subsection{Transition from Process to Performance Monitoring}

The approach described in Section 3.0 includes two phases: process monitoring and system performance (long-term) monitoring. The objective of process monitoring is to confirm the attenuation capacities and rates measured during characterization. This usually will entail traditional techniques, such as well sampling with laboratory analyses and point measurements using field sensors. Process monitoring should also set-up the transition to system performance monitoring. The transition is set up by: (1) establishing a baseline and predicted range; (2) identifying indicator parameters; (3) developing correlations between indicators and the characterization measurements; and (4) developing contingency responses.

The "predicted range" can be determined through deterministic methods, empirical methods or a combination of the two approaches (Section 4.0). This predicted range forms the basis for performance monitoring. Innovative methods to measure this "range" will be essential to performance monitoring.

\subsubsection{Monitoring Configuration/Optimization}

Transition to performance (long-term) monitoring usually involves some measure of monitoringwell-system optimization.

Environmental regulations currently prescribe a network of monitoring wells. Wells are positioned relatively near the site and are designed to detect contamination. Many wells are often required for these networks and optimizing these networks is important for economy since it may not be practical to maintain detection-monitoring networks over extended periods of time. More efficiency in monitoring may be accomplished by incorporating new strategies and approaches. Section 6.4 contains discussions of monitoring concepts that promote new strategies and approaches to monitoring. However, optimization of monitoring well networks may still be important in transitioning from process monitoring to performance monitoring.

Monitoring system configuration has been the subject of many papers, particularly in the 1990s (Andricevic 1990; Loaiciga et al. 1992; Meyer 1993) and more recent work (Chien and Murray 2003). These papers focused on using geostatistics to optimize monitoring networks.

Optimization approaches include trial and error in models, rules/data analysis, and mathematical (max, min, goals, constraints, tweaking decision variables). Mathematical optimization 
efficiently explores many combinations to find the "best" solution. The results are often nonintuitive solutions that might not be otherwise found. Examples of optimization tools that can be applied to environmental problems include gradient-based algorithms, evolutionary computation, genetic algorithms and ant colony optimization (ACO). Reed, Minsker and Valocchi (2000) used a genetic algorithm and global mass interpolation to optimize a groundwater monitoring design. "Ant colony" optimization is based on the foraging behavior of ants. It can be used to spatially optimize a monitoring network by minimizing the number of sampling locations (Chan Hilton and Li 2005). Herrera and Pinder (2005) presented a method of space-time optimization of groundwater quality sampling networks.

\subsubsection{Streamlined Compliance Monitoring and Reporting}

Automated reporting of environmental data can reduce overall costs associated with regulatory compliance of detection monitoring networks and can ultimately be used to promote the transition to system performance monitoring. Making data readily assessable to regulators and stakeholders also promotes confidence in the monitoring process. One such system is described in Case Study 7.1.

Environmental compliance activities entail obvious costs for site owners and regulators. Data acquisition, data reduction, and reporting are some of the major cost components in MNA and EA. Less recognized are the transaction costs for interactions among site owners, regulators, and consultants. Transaction costs, in this context, are the costs of making, complying with, and enforcing environmental contracts and decisions. Additional transaction costs result from public outreach and hearings. These cost sources have led to extensive development of databases and partial automation of reporting. Efficient site management requires a strategic long-term or lifecycle view, joint planning, and cooperation. 


\section{Case Study 7.1: Compliance Reporting Using Web-Based Applications}

The Americal Ecology site (http://geophysics.inel.gov/projects/ae is an example of an initial, although partial, implementation of this strategy using a web-accessible information based shared by the site owner, consultant, and regulator for various site-related purposes.

The web site has a summary compliance monitoring graph for tracking percolation performance of a test pad specified in the site permit. The web site can also be used for more detailed data examination. Regardless of the use of the information, all data for all users can be maintained in one location. Various algorithms and error analyses can be consistently tracked over time by multiple users even as requestors and generators of these analyses turn over. This allows automatic regeneration of any graph or analysis, which is often problematic in long-term projects.

The attributes of the web site application for monitoring and stewardship are: data processing and analyses; automated and on demand result delivery; a simple interface for direct access to actionable information (site compliance activities); and access to measured and calculated data. The system and data access is password controlled and access to various data or fields can be restricted to specified users. Site information can be viewed at http://geophysics/inel.gov/projects/ae. An important feature is that the stakeholders have access to the data in near-real time providing a checks-and-balance system that can potenitially increase confidence in the remedy selection.

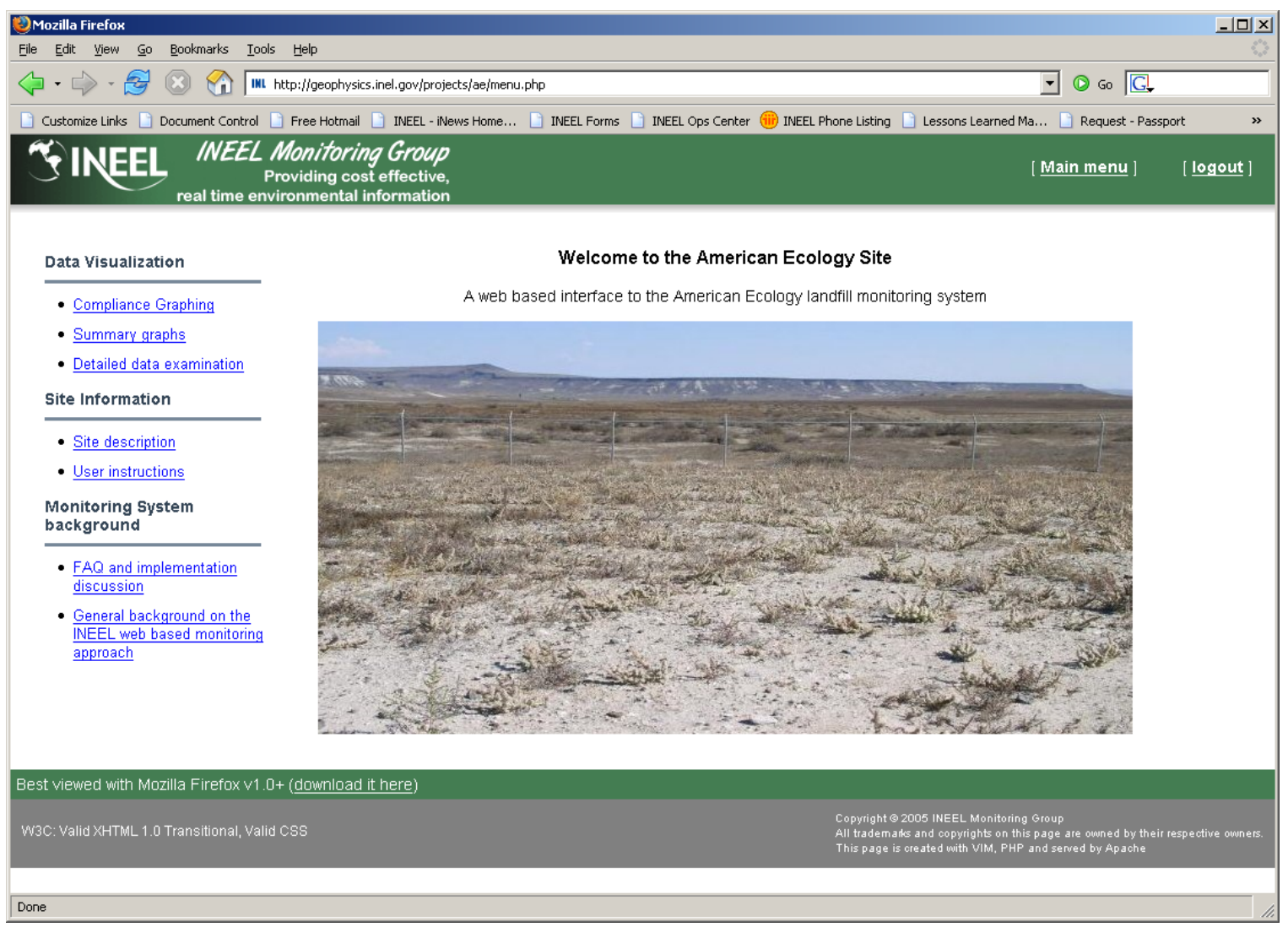




\subsection{Technologies and Concepts to Advance Performance Monitoring}

The key to performance monitoring is detecting change outside the predicted range of the baseline. Parameters may not be the same ones that were measured during characterization and they may not be collected in the same way. Change may be measured using indicator parameters (Section 7.4.1). Change can also be measured at different scales, for example, at ecosystem scales (phytomonitoring Section 7.4.2) and/or using different techniques. For example, spatially integrated measures (Section 7.5) or using alternative monitoring networks, such as alternative well configurations (Section 7.6.1) or new approaches such as "whole-earth" sensors (Section 7.6.3).

It will be important that each of these approaches can be linked back to the characterization measurements or measurements that are accepted by stakeholder and regulators. These "links" will be developed during the process monitoring stage.

If a change is detected, additional monitoring may be triggered (contingency monitoring) to determine what was the cause of the change and determine the appropriate response (contingency remedy action).

Other considerations will be the reliability or "confidence" in the system. One conceptual approach is self-checking sensor systems (Section 7.6.4).

\subsubsection{Indicator Parameters}

An indicator parameter is a parameter that is easily measured or monitored, which can distinguish a change in baseline conditions and signal that additional investigation is necessary. The Resource Conservation and Recovery Act (RCRA 1976) program uses this concept very effectively. By using a total of four indicator parameters, essentially the entire suite of hazardous wastes can be monitored and used to identify a potential contaminant release to the groundwater. The indicator parameters are total organic carbon (TOC), total organic halides, $\mathrm{pH}$, and specific conductance. Each parameter covers a broad group of chemicals, which together comprise the entire suite of hazardous materials of concern. For example an increase in TOC may represent a release of organic contamination such as hydrocarbons or chlorinated solvents. An increase over background requires additional investigations to determine the cause for the increase in TOC.

More far-reaching indicator parameters that could be used to monitor waste sites include precipitation, vegetation, stream levels, and biomarkers. While many of these will be site dependent, they can be used to monitor changes in the baseline condition and, in many cases, be correlated directly to changes in contaminant level. For example, if infiltration from rainfall is the primary driver of contamination, rainfall could serve as the indicator parameter. This parameter can be monitored in a variety of ways, but one innovative method could be to monitor leaf area of local vegetation using remote imaging from a satellite to monitor the vegetation. The ultimate goal is to identify critical indicator parameters that can be monitored easily, potentially remotely. Case Studies 7.2 and 7.3 describe innovative measures of indicator parameters and remote monitoring. 


\section{Case Study 7.2: Monticello, Utah, Superfund Site a Case Study in Use of Indicator Parameters}

Indicator parameters used to detect changes in precipitation and vegetation could be adapted to monitor changes in baseline conditions at MNA waste sites. An example is the monitoring for an alternative engineered cover at the Monticello, Utah CERCLA site. The cover includes a soil/vegetative layer to promote evapotranspiration (ET) over a capillary barrier. The purpose of the capillary barrier is to enhance water storage in the soil/vegetative layer and to minimize unsaturated flow through the site. The design relies on the water-storage layer to retain precipitation until it is seasonally removed by vegetation. Methods used to evaluate the performance of the cover system are lysimeters and natural analogs. Both of these will be examined briefly.

A series of field lysimeter experiments were conducted to help design and monitor the performance of the Monticello cover. The lysimeter test facility evolved as a sequence of installations, first to test the concept of using an ET/capillary barrier cover design at Monticello, next to evaluate the soil-water balance of the design, and finally to monitor the hydrologic performance of a large facet of the completed cover. In 1990, small weighing lysimeters containing undisturbed native soils, a capillary barrier and supporting native grasses were installed. Leaf water potential, leaf transpiration, and whole-plant gas exchange of plants growing in and adjacent to the lysimeters were compared to test the physiological responses of plants to confinement in the small lysimeters. Favorable results led to construction of an array of 15 additional small weighing lysimeters in 1993 to compare drainage, ET, and water-storage capacities of cover designs with varying soil types and soil layer thickness. The resulting data led to the final cover design for Monticello.

In 1999, DOE teamed with EPA on a study using large caisson lysimeters to evaluate the hydrological and ecological performance of the Monticello cover as built. Covers constructed inside the caissons matched the range of conditions as built in the actual cover. Finally, in 2000, DOE and EPA collaborated on installation of a large drainage lysimeter under a 3ha facet of the 14-ha disposal cell cover at Monticello. Both studies showed that plant transpiration has kept drainage flux levels well below the EPA target of $3.0 \mathrm{~mm} / \mathrm{yr}$.

The Monticello site operations team is demonstrating methods based on global change models and paleoecological evidence to establish a first approximation of possible future climatic states. A preliminary analysis of paleoclimate data for Monticello yielded average annual temperature and precipitation ranges of 2 to $10{ }^{\circ} \mathrm{C}$ and 80 to $60 \mathrm{~cm}$, respectively, corresponding to late glacial and mid-Holocene periods. Instrumental records were used as a basis for selecting soil and vegetation analog sites that span a reasonable range of future climate scenarios for Monticello. Natural and archaeological soils that are considered representative of pedogenic changes in engineered cover soils are being characterized. For example, key soil physical and hydraulic properties at natu measured to infer possible future pedogenic changes in th

The indicator parameters employed at the Monticello site are distinct examples of monitoring the performance of a system. The lysimeter data provides an indicator of cover system integrity. Water collected in the lysimeter at a rate greater than the operational envelop would be an indicator of loss of integrity of the cover system. This type system would support system performance monitoring of several types of Enhanced Attenuation processes. The use of natural analogs in predicting future changes to a system would support system performance monitoring of both sites in a condition of MNA and sites where EA processes have been deployed.

Archaeological Analog for the Monticello Site: Soil Morphology and Hydrology

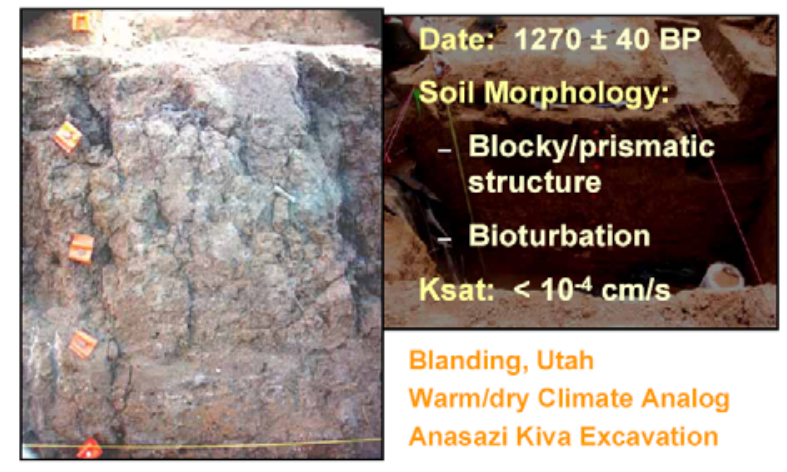




\subsubsection{Phytomonitoring}

Frederick Clements (1920), the eminent U.S. botanist, explained that plants are integrators of environmental factors when he stated: "Each plant is an indicator. This is an inevitable conclusion from the fact that each plant is the product of the conditions under which it grows, and is thereby a measure of these conditions. As a consequence, any response made by a plant furnishes a clue to the factors at work upon it." Therefore, plants growing on or surrounding a contaminant site can be leading indicators of changes in the environment and water infiltration at the site.

\section{Plant Density, Mortality, and Shoot}

Length. Plant density is the number of individual plants in a given area or the reciprocal of the mean area of space per individual plant. Density is a historically important measure of plant abundance, especially for trees and shrubs. However, density alone is not a good measure of plant health or dominance in a community. Mortality, the percentage of dead individuals, can be related to many factors, including age structure of the population, intra-specific competition in high-density (crowded) stands, and environmental stress factors such as drought, pests, and exposure to toxins. New shoot growth and annual biomass productivity can also be indicators of relative plant health on a cover.

\section{Leaf Area Index and Foliage Density.}

Measurements of plant canopy structure are often used to compare functional attributes of plant communities. Plant canopy structure plays a fundamental role in processes involving the interaction of plant communities and their environment, including processes such as evapotranspiration (McNaughton and Jarvis 1983), biomass productivity (deWit 1965), and radiation interception (Ross 1981). Plant canopy structure can be thought of as the amount and organization of aboveground plant material. Canopy structure may include the size, shape, orientation, and distributions of various plant parts such as leaves, stems, branches, flowers, and

\section{Case Study 7.3: Thermal Imaging as Indicator of Groundwater Discharges}

Contaminated groundwater seeps or groundwater discharges points into surface waters are difficult to detect visually. During the winter, groundwater insulated from surface temperatures tends to be warmer than the colder surface waters. This temperature differential means surface waters are colder than groundwater. Thermal infrared (TIR) imaging has been used to identify groundwater seeps (Portnoy et al. 1998; Torgersen et al. 2001). For example, Portnoy et al. (1998) used TIR imaging to locate nitrate contaminated groundwater discharge to a freshwater marsh. Torgersen et al. (2001) used TIR imaging to assess the spatial pattern in stream water temperature. TIR imaging captures only the thermal energy at the surfaces; seeps that are submerged and allow bulk mixing with overlying surface water often cannot be detected using this technique.

TIR imaging was used to identify groundwater seeps contaminated with VOC's along West Branch, a freshwater tidal creek, at the Aberdeen Proving Ground (Lorah 2002). The TIR techniques collect digital video and still images. Low altitude aerial TIR surveys were conducted during low tide by helicopter to identify suspected seeps. Identified sites were verified by TIR surveys conducted from the ground and boat at low tides. The ground TIR surveys were also conducted to identify locations not observable from the helicopter TIR surveys. The TIR surveys clearly identified seeps along tidal streamlets as well as point sources. Identified locations were sampled by Passive Diffusion Samplers and co-located surface-water samples. 
fruits. The amount of leaf material in a canopy can be represented by measurements of the leaf area index (LAI). LAI is an important plant canopy parameter for evaluation of plant water relations and is a key input parameter for most models of soil water balance and recharge. Transpiration rates can be empirically linked to the green leaf area of a plant stand.

Chlorophyll Fluorometry. Chlorophyll fluorometers are instruments for measuring plant stress and have also been advocated for a variety of evapotranspiration cover and phytoremediation applications (Richter et al. 1998; Barocsi et al. 2000; Waugh and VanReyper 2003). The BUTE chlorophyll fluorometer, also referred to as CFM-636973 (CFM), measures temporal variation in chlorophyll fluorescence. This process, called Kautsky kinetics (e.g., Krause and Weis 1984), is a measure of the ability of a plant to convert chlorophyll from its dark or inactive form to its light or active form. Sources and severity of plant stress influence the rate and nature of this conversion. The CFM excites plant leaves at $635 \mathrm{~nm}$ and measures a variety of fluorescence parameters at 690 and $735 \mathrm{~nm}$ that are indicative of different physiological responses. Different combinations of fluorescence parameters can be analyzed to detect different environmental stressors, including water deficiency, temperature, photoinhibition, nutrient deficiency, and chemical stresses. Therefore, the CFM can be applied as a diagnostic tool for evaluating plant stresses and environmental tolerances.

\subsection{Spatially Integrated Measures}

Direct measures include other critical parameters that are used to assess MNA including flux measurements, advective flow conditions, and temporal and spatial variations. These parameters are larger scale, spatially integrated measurements that may be most effectively measured in an integrated fashion rather than using point measurements. Sensors and high frequency data collection may not be the most efficient and cost effective methods to determine these parameters. Contaminant flux, geochemical footprints, and other averaging methods may rely on geophysical techniques or remote sensing devices that spatially integrate data. It may be necessary at the outset to correlate spatial measurements with point measurements in order to establish a baseline from which to evaluate change using the spatially integrated measures. These measures and their use are technical targets for research and development.

\subsubsection{Geophysical Methods in Monitoring MNA}

Research on the applicability of geophysical methods for monitoring natural attenuation processes has been very recent. In the past year, results of a number of studies have been published describing how different geophysical methods, ranging from seismic techniques to measurement of passive electrical signals, can be used to improve monitoring of natural attenuation. Of the several methods described in recent geophysical literature, the category of electrical geophysics appears to be the most highly developed in terms of conceptual framework and through combined laboratory and field results. Three different electrical methods--direct current resistivity, induced polarization and self-potential--appear to have merit. The first two techniques are active, in that they require electrical current to be injected into the earth; selfpotential is passive, and uses naturally occurring electrical potentials. Other geophysical techniques used to monitor contaminant migration in the subsurface include ground penetrating radar and time domain reflectometry (TDR) (Brewster et al. 1995). 
Geophysical monitoring techniques require: (1) a conceptual and theoretical framework that supports the method, (2) demonstrated effectiveness, (3) cost-efficient performance, and (4) the ability to be used for a reasonable time period.

Direct Current Electrical Method. The possibility of using the direct current (DC) resistivity method for monitoring natural attenuation arose from multiple field investigations of hydrocarbon contamination. Generally, hydrocarbons are electrically resistive. Near a source of hydrocarbon contamination, the DC resistivity survey can show a high resistivity anomaly, whereas further down gradient, the more mature hydrocarbon plume appeared electrically conductive (low resistivity). Sauck $(1998,2000)$ hypothesized that hydrocarbon-degrading bacteria were indirectly responsible for the low resistivity. This hypothesis has been supported in subsequent work (Cozarelli et al. 2001; Werkema 2002; Atekwana et al. 2003).

The Hanford site conducted a high-resolution resistivity survey to identify waste leakage from high-level radioactive waste tanks. The waste was highly conductive (low resistivity) because of the high salt content of the liquid waste and the waste plumes could be effectively mapped (AGI 2005). Resistivity methods can be adapted to a monitoring configuration where an electrode array is deployed and periodically measured to monitor for changes from a baseline. An example application is use of a resistivity network at the Gilt Edge mine in South Dakota to monitor for ground-water movement (Versteeg 2005). It was found that changes in the electrical data are indicative of subtle volumetric changes and processes.

Induced Polarization Method. The induced polarization (IP) method is similar in field setup to the DC resistivity method. However, because measurements are made at more than one frequency, IP equipment tends to be more complicated and expensive than DC equipment. In the spectral IP method, the magnitude of the voltage yields apparent resistivity as in DC measurements. In addition to this, the phase-lag between the applied current and voltage is measured and is thought to be diagnostic of the nature of sub-surface mineralization. Measured frequencies may range from 1000 s to $0.001 \mathrm{~Hz}$.

Vanhala (1997), in laboratory spectral IP measurements on clean and oil-contaminated sands and tills, found that the phase spectra of the clean sands and tills remained stable over time, but the spectra of the oil-contaminated sands and till changed with time. Though not addressed in the paper, these changes could have been a result of biodegradation processes in the contaminated materials. A more recent laboratory study by Abdel Aal et al. (2003) on hydrocarbon contaminated cores produced phase spectra in contaminated cores that were an order of magnitude larger than for uncontaminated samples. Examination of mineral grains of the samples under a scanning electron microscope revealed that the grains in the contaminated zone were considerably more etched and pitted than grains in the uncontaminated region (Burton et al. 2003). Mineral texture is thought to be a controlling factor in IP phase lag, so pitting and etching of mineral grains by organic acids derived from hydrocarbon degradation could be the cause of the observed phase differences.

Installation of long-term monitoring stations with fixed electrodes is more difficult with IP than with DC resistivity because of the necessity for non-polarizing electrodes. These take the form 
of small porous pots containing a copper sulfate solution. Long-term upkeep of a large network of porous pot electrodes could be time consuming, but may be manageable.

Self-Potential Method. As with the IP method, self-potential (SP) uses porous pot electrodes to measure voltage differences. However, unlike the two previously discussed methods, SP does not have an active source of electrical energy. The SP method is passive, measuring naturally occurring potential differences. These potentials may arise from subsurface flow of ionic fluids (tens of $\mathrm{mV}$ ), adsorption of ions to mineralized surfaces (tens of $\mathrm{mV}$ ), differences in ionic concentration (tens of $\mathrm{mV}$ ), bioelectric activity (hundreds of $\mathrm{mV}$ ), or mineral potentials (hundreds to thousands of mV). Recent work by Naudet et al. (2003) has developed SP as a subsurface redox zonation-monitoring tool (Case Study 7.4). Versteeg et al. (2005) have developed automated processing of SP data for real time visualization and decision making.

\section{Case Study 7.4: Estimating Redox Potential from Self-Potential Measurements}

Subsurface redox potentials are useful for understanding plume migration, plume evolution, and risk. While self potential (SP) measurements have long been used in geophysical mining applications, recent work by Naudet et al. (2003) has developed SP as a subsurface redox zonation monitoring tool.

A laboratory test showed an initial aerobic consumption of oxygen by the biological processes followed by sulfate reduction and fermentation of the remaining lactate. This plume showed a slow downward movement of the plume due to a small density contrast.

Naudet and coworkers used a field network of lead chloride electrodes to monitor SP in groundwater. Contaminant flow migration was tracked by the direction of movement of an apparent redox anomaly while changes in biological activity and associated biochemical transformations were inferred from step changes in SP. These were confirmed in laboratory redox tests. This work was performed at the Entressen municipal waste landfill near Marsailles in southeastern France and represents an area of over $20 \mathrm{~km}^{2}$.

In contrast to the near static flow in the laboratory experiment, an electrokinetic component resulting from the flow of ion-containing water past charged surfaces in the aquifer also had to be considered and characterized. This electrokinetic component needs to be removed from the SP before redox effects could be quantified. In general, electrokinetic coupling depends upon groundwater velocity, ionic composition of groundwater, and aquifer characteristics. Specifically, in the aquifer they studied the streaming potential was empirically related to hydraulic head differences in the local aquifer. The measured slope between the two potentials yielded a coupling coefficient between measured hydraulic heads and measured voltages or SPs. The SP residual component showed a strong relationship between SP and laboratory measurements of redox potential. The results are intriguing despite uncertainty in both the redox potential-SP linkage and the laboratory measures of redox potentials. 


\subsubsection{Accumulators/Integrative Samplers}

Accumulators are materials (or biota) that accumulate or collect a contaminant they are exposed to by passive partitioning. When exposed for a known period of time, the resulting concentration of the accumulator can be related to flux or contaminant discharge. These are sometimes also referred to as integrative sampling techniques when used to determine organism exposure to contaminants.

Accumulators have significant advantages over point measurements for long-term monitoring and address many of the desired attributes for long-term monitoring previously listed. In general, passive partitioning processes provide a time-weighted average of contaminant discharge, can sequester a broad spectrum of chemical classes, concentrate pollutants often metabolized by organisms, and can be used in surface water, sediment and groundwater environments. Media used as passive accumulators include carbon, selected plastics (Lefkovitz et al. 1996) and semipermeable-membrane devices (SPMD) (Echols et al. 2000; Wang et al. 2002). Depending on the absorbent material and media, the samplers can be used to relate contaminant discharge to environmental risk by quantifying accumulation in the environment. Case Study 7.5 presents such a passive integrative sampling device.

\section{Case Study 7.5: Passive Integrative Sampling Approach \\ A suite of passive samplers has been developed that uses an integrative sampling approach for waterborne contaminants to assess the presence and potential toxicological significance of environ- mental contaminants. The samplers are made of various materials (commonly plastic) that absorb contaminants. The samplers are then analyzed after deployment to measure exposure and have been deployed with good success. One example is their deployment in a constructed wetlands to determine the effectiveness of the wetland in removing contaminants (Johnson et al. 2004). These types of passive samplers may also be adapted to long-term monitoring of MNA. \\ Some of the advantages of these samplers over currently employed techniques are their ability to integrate concentration over time, their sensitivity to trace concentrations, and their durability in comparison to live organisms sometimes used for monitoring.} coupling abiotic accumulators with remote sensing. An accumulator that emits an electrochemical signature might be measured remotely (e.g., satellite imaging or from the air).
Some sessile animal species such as clams are natural accumulators. Most aquatic organisms accumulate chemicals by ventilation of water or by skin absorption, through the food web, and/or through direct ingestion of contaminated sediment (Wang et al. 2002). Materials that passively accumulate contaminants are analogous to biological uptake in the environment and can also be used for assessing the bioavailability of contaminants. Relating contaminant discharge (flux) to risk will be important at many sites. A limitation, however, is that it is often difficult to directly quantify contaminant flux using these biomarkers because variables such as metabolism are difficult to account for. For example, the metabolism of clams can vary based on water temperature, depth, and light. An abiotic adsorbent could be used to help quantify what the clams are being exposed to and in concert with clams or other biota to make that link of contaminant discharge (flux) to risk.

One technical target is the possibility of 
Alternatively, a device that fluoresces in the presence of a contaminant may be monitored. Remote measurement could be qualitative, i.e., an "on or off" signal, or it may be quantitative.

\subsubsection{Remote Sensing}

Aerial remote sensing (ARS) technologies hold promise for monitoring contaminant sites. Remote sensing can be used to monitor surface expressions of contaminants in wetlands, streams and seeps through thermal imaging and other techniques. Remote sensing can also be used to monitor indicators of system changes and "health". For example the Corp of Engineers monitors offshore dredging spoils by aerially monitoring the ecological health of eelgrass on the underwater capped spoils. Changes in the plant community can indicate breeches in the caps. Similarly, changes in vegetation and moisture conditions on disposal cell covers are leading indicators of failure scenarios. Changes in the vegetation composition, abundance, health, and evapotranspiration can be indicated by differences in spectral reflectance and can be quantified using aerial remote sensing technologies. ARS data can be used to detect vegetative change from one growing season to the next, from year to year, or from decade to decade. Patterns in surface and subsurface soil moisture may also be interpreted from quantification and interpretation of spectral reflectance data. The premise is that if development of surface anomalies and other changes in surface patterns indicating a change in cover performance can be detected early and inexpensively using ARS technologies, then the anomalous or suspect areas can be targeted for more intensive in situ investigation and repairs, if needed, before a failure occurs requiring a more expensive corrective action and possibly averting non-compliance of an approved regulatory permit.

\subsection{Alternative Monitoring Networks}

Alternative monitoring networks also provide opportunities for efficient performance monitoring. Horizontal wells, for example, may enable a more spatially integrated access to some sites. In many, if not most sedimentary geologic environments, formations are horizontally layered and plumes are controlled in large part by the geology. At such sites a horizontal well can potentially interrogate a larger cross-section of the plume. Other alternative networks could include diffusion tubing or "whole-earth" sensors (Section 7.6.3) where the ground itself becomes the "sensor". These alternative networks in most cases need further technical development but are presented here to illustrate the possibilities.

\subsubsection{Alternate Well Geometries, Horizontal Wells}

An alternative to spatially integrated monitoring is to interrogation of a larger cross section of the subsurface. Alternative well geometries and access approaches (such as horizontal wells) may prove useful in designing and implementing robust monitoring systems for MNA/EA (see summary information in DOE 1998 and EPA 1994). Such potential is apparent in the typical shape of subsurface plumes. A TCE plume underlying M-Area of the DOE Savannah River Site in South Carolina tends to migrate downward and then horizontally in a relatively thin but laterally extensive zone. In this case, access to this plume may best be accomplished with a horizontal well rather than a series of vertical wells. Once the site is characterized, a monitoring network could be established using much fewer horizontal wells than vertical wells to provide the essential monitoring. 
Clean-up systems based on naturally sustainable processes, such as MNA/EA, generally require long periods of time and depend on plume stability, contaminant flux, and risk reduction/ management. Because of the typical geometry of subsurface plumes, large numbers of vertical wells, each with a short screen, are needed for adequate coverage. Alternative geometries and integrating methods are available - examples include horizontal well or trench based sampling, stream sampling, surrogate sampling, and ecosystem level and remote sensing sampling. These have the added potential of providing a more direct measure of flux. For example, in a thin laterally extensive plume, a horizontal well can be placed along an isopotential line. The relative flow into any segment of the well will be proportional to the relative hydraulic conductivity near that segment. Thus, the composite concentration from this one sample access would integrate the concentrations and relative flows into a value that would closely correlate with flux. This concept can be combined with emerging sensors in innovative ways.

Serious scientific investigation of environmental horizontal drilling began in the 1980s and costs have declined since that time; current costs are in the range of 3 to 20 times vertical drilling costs. There are several potential issues and challenges that accompany this approach. Some of these are practical - installation of horizontal wells or trench collection systems often requires a robust drilling mud to maintain hole stability and drilling often uses large amounts of drilling fluid. It must also be determined if the well must be properly developed or, if drilling fluids containing organic materials are used, will the well produce representative chemical or microbiological data. Also, if there are pressure differences from one part of the well to another, then water will flow along the well and provide poor information and a potential conduit for contaminant migration. While this issue is present in vertical wells, a long screen length might exacerbate it. This might result in the need for isolation systems and other technologies that would increase complexity and cost. Despite these limitations, well and access geometry should be considered in developing new long-term monitoring techniques.

\subsubsection{Diffusion Tubing}

A new area of research uses permeable membranes to interrogate the subsurface environment. Contaminants will naturally diffuse under a concentration gradient through materials such as low-density polyethylene, silicone materials and other plastics. By placing chambers or tubing in the ground with permeable membranes, contaminants will diffuse into the chamber or tubing allowing the vapor concentration (or aqueous phase) in the chamber to be sampled. The nuclear industry monitors steam piping using diffusion tubing. Steam from the leak diffuses into a sensor hose and is transported with air inside the hose to a moisture sensor that calculates the size and location of the leak from the measured moisture level and the transport time (Framatone ANP). The FLÜS moisture-sensitive leakage monitoring system detects even tiny leaks from components containing steam and determines their location extremely precisely. Diffusion tubing has also been used in the environmental industry to deliver reactants, nutrients, tracers and other constituents to the subsurface for remediation and characterization. Permeable tubing has been used inside a well to release solutes (Wilson and Mackay 1995), to deliver oxygen to a well (Gibson et al. 1998) and most recently for delivering a solute through nylon tubing (Arildskov and Devlin 2000). Siemons (1998) deployed diffusion tubing (LDPE) in wells around a landfill to collect gases and then analyze the gas concentration in the tubing. Recent research by Gilmore and Oostrom (1999) extended the development by placing the tubing in direct contact with the subsurface as opposed to deployment in a well. Tubing can be placed perpendicular to 
the direction of contaminant plume movement and used to monitor concentrations in the plume. Various sampling techniques could be used; composite sampling of the plume front, or the precise location and concentration of contamination could be identified by measuring concentrations and travel times in the tubing.

\subsubsection{Whole-Earth Sensors}

Gilmore (2001) proposed augmenting the subsurface with materials that will accentuate a geophysical signature. While this concept needs further development it does illustrate the possibilities of spatially integrated measurements. The whole-earth concept is to add a material to the subsurface that will interact with a contaminant so that the electrical and/or magnetic properties of the subsurface will be measurably altered and easily monitored. Potential materials include graphite, polymers, zeolites, and catalysts. These materials will react with specific contaminants altering their electrical conductivity or in some cases magnetic properties. These changes would be monitored using the standard geophysical electrical resistivity and electromagnetic methods.

For example, graphite in the form of micron-sized soot particles could be injected around a perimeter of a burial ground or landfill. Alternately, the graphite could be mixed in backfill around the waste sites. When organic contamination leaks from the waste site and contacts the graphite, the graphite will adsorb the organic. By adsorbing the organic, the graphite structure expands, and the conductivity of the material is measurably changed. This change could be measured by electrical resistivity methods that use short electrodes or conducting rods at the ground surface. The electrodes provide low voltage DC current and are used to measure the voltage and intensity of the current. A deviation from the established baseline in the subsurface electrical properties would indicate that the waste site has released contaminants and additional action is required. Additional materials that have been considered are catalysts that are nonreactive with common subsurface constituents such as sodium, calcium, and potassium, but are reactive with contaminants such as chromium and manganese and potentially technetium. Zeolites and Samms particles could be used to selectively adsorb selective molecule sizes making it possible to detect select contaminants. Other possible materials include iron that is conductive, but iron oxides are not. A contaminant that promotes oxidation could potentially be detectable.

The benefits of this approach are that the detection method is simple (there is no sensor method simpler then measuring electrical resistance), it is relatively cheap, and easy to maintain and operate. In addition, spatially integrated measurements are possible (as opposed to point source measurements in wells) minimizing the chance that a leak will go undetected by a monitoring well system. This measurement system is also non-intrusive and can be measured remotely, all criteria for long-term monitoring.

\subsubsection{Self-Checking (Safe Positive) Sensor Systems}

Most sensors provide a positive response when they detect something. For example, a sensor designed to detect contamination provides a signal only when contamination is present. A positive signal causes an alert that indicates the problem. In the absence of a signal, it is therefore assumed that there is no contamination. If the sensor system fails, however, because of a broken wire, interference or other malfunction, the result is a false negative; the system will "miss" the 
contamination. For this reason a long-term performance-monitoring network based on sensors that provide a positive signal for detection may not be the best approach.

An alternative would be to use a network of sensors that provide positive (safe) signals when no contamination is detected. With such a system the sensor signal would be on at all times, reflecting no breach of containment and no malfunction. In the presence of a contaminant the signal would turn off providing an alert that the site needs attention. Furthermore, a broken wire, interference or other malfunction in the system would also signal a need for attention. Such a self-checking system based on "safe positives" would reduce the possibility of missing contamination and increase confidence that the detection-monitoring network is performing properly.

\subsubsection{Potential Alternative to Spatially Integrated Measures}

The primary drawback to using point source measurements to estimate flux and temporal and spatial variations is that the number of measurements required to reduce uncertainty to an acceptable level can be expensive and labor intensive. Although a spatially integrated approach can address these issues as discussed in Section 7.5, a parallel approach should be considered for collecting abundant, inexpensive, easily obtainable data. This solution would require technology development but does offer an intriguing alternative. Case Study 7.6 illustrates an example of the concept of collecting abundant inexpensive data.

\section{Case Study 7.6: Abundant Data Solution}

Using a network of microcomputers to monitor natural attenuation would depend on the development and innovative use of sensors. Several groups including INTEL, DARPA, and universities are developing a new class of thumb-size microcomputers, called motes. The thumb-size mote is a combination of microprocessor, memory, sensors, and radio transceiver. Motes could process, store, and transmit sensor data collected from sites where natural attenuation is being monitored.

The mote functions under an operating system called TinyOS, which can communicate with other motes via a wireless connection. Attached sensors, which can detect temperature, humidity, light, vibration, acceleration, atmospheric pressure, and RFID tags are already available. Motes are relatively inexpensive and the placement of many motes in the environment can allow the monitoring of large areas very inexpensively. For example, a network of motes has been used to monitor the microclimate conditions of a redwood tree. In another study, a network of motes was used to monitor the nesting locations of petrels. In a third application, Intel is placing motes in one of its factories to monitor machinery for signs of wear and failure. Motes conserve battery power by sleeping $99 \%$ of the time, flicking on a radio several times a second then turning off within milliseconds. Motes typically have a hardened shell, which protects them from the environment, but if a mote fails, the network automatically reconfigures itself to account for the change in the connectivity.

For more information on motes, see Smart Sensors to Network the World (Culler and Mulder 2004). 


\subsection{Technical Targets and Conclusions}

MNA will be most effectively implemented in the context of the overall natural systems approach that accounts for all the key interactions between the plume and the environment. The challenge is to identify the most reliable and cost-efficient characterization and monitoring tools, methods, and processes. High-priority areas for research and development are techniques to measure contaminant flux, more direct measures of critical parameters particularly direct measures of attenuation, adapt spatially integrated measures for monitoring, and develop new monitoring strategies that are not based on detection well networks. Technical targets for advancing the characterization and monitoring of MNA are listed in Table 8.1 and highlighted in the following paragraphs.

There is currently no direct measure of biodegradation, one of the principal natural attenuation mechanisms for chlorinated solvents. Instead, indicators such as chemical conditions suitable for biodegradation and breakdown products provide evidence of biodegradation. One of the most significant improvements to the characterization and monitoring of MNA would be the direct measure of contaminant degradation, i.e., measuring directly the presence of the microbes that degrade the contaminants of concern, as well as their activity. Molecular tools currently under development hold promise in this area (Section 6.0).

Another factor that will impact the acceptance of MNA and, therefore, is a technical target is the proven ability to measure flux, evaluate the uncertainties associated with those measurements, and establish that reliable precision in assessing mass balance can be attained. From a practical standpoint, the approaches must also be cost effective. Mass flux is very difficult to measure, which results in the current reliance on point source measurements. A significant technical advance would be to develop methods to more directly measure flux (Section 6.2).

A related critical development area is spatially integrated measurements: measuring contaminant concentrations throughout a sample area or volume rather than at discrete points. These include geophysical methods that interrogate a subsurface area, remote sensing strategies, alternate well geometries, subsurface interrogation approaches (i.e., diffusion tubing and whole-earth sensors), and passive or accumulator sampling. These subsurface techniques can rely on natural properties or altered properties that accentuate the measurements. These types of measurement will promote alternate strategies to performance or long-term monitoring (Section 7.0).

Monitoring strategies that go beyond optimizing detection-well networks need to be developed. This includes combining new and developing technologies with comprehensive approaches in monitoring with increased focus on system-wide monitoring. One example of these alternative strategies is utilizing the concept of "safe-positive" monitoring outlined in Section 7.4.

As part of this development there will also be the need for strategies that allow the transition from the detection-well monitoring networks to more "natural system" approaches. Examples include the development the optimizing techniques for monitoring well networks (Section 7.3.1) and automated monitoring (Section 7.3.2). 
Table 8.1. Summary of Technical Targets

\begin{tabular}{|c|c|}
\hline Technical Target & Example \\
\hline Direct measures of attenuation & Section 6.1 \\
\hline $\begin{array}{l}\text { Methods to more effectively measure or estimate } \\
\text { flux }\end{array}$ & Sections $6.1 .3-6.2$ \\
\hline $\begin{array}{l}\text { Apply mathematical optimization techniques to } \\
\text { monitoring }\end{array}$ & Section 7.3 .1 \\
\hline Spatially integrated measures & Sections 7.5 \\
\hline \multirow[t]{5}{*}{ Develop long-term monitoring techniques } & Passive samplers - Section 6.2 \\
\hline & Accumulators - Section 7.5.2 \\
\hline & Remote sensing - Section 7.5.3 \\
\hline & Diffusion tubing - Section 7.6.2 \\
\hline & Whole earth sensors - Section 7.6.3 \\
\hline Non-conventional monitoring networks & $\begin{array}{l}\text { Horizontal well, diffusion tubing - } \\
\text { Sections 7.6.1, 7.6.2 }\end{array}$ \\
\hline Environmental systems approach & Indicator parameters -7.4 .1 \\
\hline $\begin{array}{l}\text { Monitoring strategies (alternatives to monitoring } \\
\text { well systems) }\end{array}$ & $\begin{array}{l}\text { "Self Checking" Monitoring Systems } \\
\text { 7.6.4 }\end{array}$ \\
\hline
\end{tabular}

Scientific and technical advances have been made since the original protocol (EPA 1998) on diverse topics ranging from subsurface access, to ecosystem structure and function, to bioassessment tools. Incorporation of some of the more critical advances will advance the use of MNA.

Two overarching concepts may improve the current baseline method for characterization and monitoring of MNA and enhanced attenuation. These are a phased approach to characterization and monitoring and the explicit use of mass balance.

Conceptualizing MNA as a balance between contaminant loading and attenuation allows the process to be quantified using mass balance equations. This mass balance concept will not only focus the characterization and monitoring but also provide a framework to explain the process to stakeholders. In essence, MNA is viable if the sum of the various mechanisms is sufficient to attenuate the contaminants and protect potential receptors. Characterization provides evidence that the attenuation capacity in the system is sufficient and sustainable and monitoring verifies the attenuation capacity is sustainable. 
The mass balance can be observed (empirical approach) or formulated in terms of the physical, chemical, and biochemical processes and solving mass balance equations for each contaminant (deterministic approach). The empirical approach is most useful in determining the overall natural attenuation capacity of a system at a particular point in time. But while the empirical approach is useful for documenting the past behavior of a system, it is less useful for making predictions concerning future behavior. This is particularly true at sites under active remediation, which are not in natural equilibrium. To make such estimates of future behavior, the time-dependent mass balance equations of the deterministic approach is more appropriate. In practice, the most reliable way to assess natural attenuation capacity and the future behavior of a contaminated site is to employ a combination of the empirical and deterministic approaches. Each method offers unique, complementary advantages.

In order to best apply the mass balance approach, additional research and the development of new characterization methods will be required. If the traditional monitoring techniques are used, the cost of MNA may be too high. Critical areas of development include direct measures, spatially integrated measures, flux measurements, and the development of non-traditional monitoring networks that reflect the attributes of long-term monitoring. Cost savings will be realized through efficient application of the existing and new characterization and monitoring technologies and strategies.

Another critical need is conceptual approaches and tools for long-term monitoring. Nontraditional monitoring systems are needed for efficient long-term monitoring of natural attenuation. Monitoring, particularly long-term monitoring using traditional methods, is a primary cost of MNA. With many sites leaving waste in the ground to naturally attenuate it will become even more important to adapt methods that make monitoring as effective and efficient as possible. The purpose is to have techniques and approaches in place that will reduce costs while maintaining the ability of managers and stakeholders to make reliable decisions. 


\subsection{Afterword}

A classic science fiction story by Arthur C. Clarke (1983) develops the concept of a unique longterm monitoring technique. In his story, Sentinel, Clarke detailed man's exploration of the moon. While exploring the moon, astronauts happen on an unusual device that emits energy. The astronauts' curiosity leads them to figure out how to turn the energy emission off and take a closer look at the device. What they found was a transmitter that stopped transmitting when they got close. Whoever was monitoring the device knew that when the transmission stopped, there was either a mechanical malfunction that needed attention or that humans were slowly moving across the solar system. Essentially, the device was designed to monitor human progress.

While we shouldn't necessarily equate man's progress across the solar system to contaminant migration, the concept of using a "safe-positive" (i.e., the signal turns-off) when something is detected as opposed to our current monitoring techniques that use a "false-negative" technique (i.e., the signal turns on if something is detected) is applicable to long-term monitoring. We use sensors that turn on when they detect something; however, the weakness in this approach is that if they have a mechanical problem, a wire is broken or power goes off then nothing is "detected" (i.e., the sensor does not "turn-on"). Over the long-term, mechanical problems and other glitches need to be considered. New strategies that put monitoring in the context of long-term monitoring need to be considered. We need to shed our current paradigm of environmental monitoring that has been centered on characterization techniques and develop new strategies for long-term monitoring. 


\subsection{References}

Abdel Aal GZ, EA Atekwana, LD Slater, and C Ulrich. 2003. "Induced Polarization (IP) Measurements of Soils from an Aged Hydrocarbon Contaminated Site." SAGEEP 2003 Proceedings, 190-200.

AGI. 2005. Resistivity Survey at the Hanford Site, Richland, Washington. Advanced Geosciences, Inc. Austin, Texas. Available online at http://www.agiusa.com/brochure_HanfordSite.shtml

Andricevic R. 1990. "Cost-Effective Network Design for Groundwater Flow Monitoring." Stochastic Hydrology and Hydraulics 4(1):27-41.

Arildskov NP and JF Devlin. 2000. "Field and Laboratory Evaluation of a Diffusive Emitter for Semipassive Release of PCE to an Aquifer." Groundwater 38(1):129-138.

Atekwana, EA, EA Atekwana, and RS Rove. 2003. "Relation Between Total Dissolved Solids and Bulk Conductivity at a Hydrocarbon-Contaminated Aquifer." SAGEEP 2003 Proceedings, 228-237.

Aziz CE, CJ Newell, JR Gonzales, P Haas, TP Clement, and Y Sun. 1999. BIOCHLOR Natural attenuation decision support system v1.0. User's Manual. EPA 600/R-00/008, U.S. Environmental Protection Agency, Washington, DC.

Ballard S. 1996. "The In Situ Permeable Flow Sensor: A Groundwater Flow Velocity Meter." Groundwater 34:231-240.

Barocsi A. L Kocsanyi, S V'arkonyi, P Richter, Z Csintalan, and K Szente. 2000. "TwoWavelength, Multipurpose, Truly Portable Chlorophyll Fluorometer and Its Application in Field Monitoring of Phytoremediation.” Meas. Sci. Technol. 11:717-729.

Brewster ML, AP Annan, JP Greenhouse, BH Kueper, GR Olhoeft, JD Redman, and KA Sander. 1995. "Observed Migration of a Controlled DNAPL Release by Geophysical Methods." Ground Water 33(6): 977-987.

Burton T, EA Atekwana, and EA Atekwana. 2003. "Mineral Grain Surface Observations at a Hydrocarbon-Contaminated Aquifer: Implications for the Geoelectrical Properties of Soils." SAGEEP 2003 Proceedings, 271-280.

Carey, G. R., P. J. VanGeel, T. H. Wiedemeier and E. A. McBean. 2003. "A Modified Radial Diagram Approach for Evaluating Natural Attenuation Trends for Chlorinated Solvents and Inorganic Redox Indicators." Groundwater Monitoring and Remediation, 23(4):75-84. 
WSRC-STI-2006-00084, Rev. 1

August 1, 2006

Page 48 of 53

Chan Hilton AB and Y Li. 2005. Development of Ant Colony Optimization Algorithm for Groundwater Monitoring. GECCO ’05, June 25-29, 2005, Washington, DC.

Chapelle, Francis H. and Paul M. Bradley. 1999. Selecting Remediation Goals by Assessing the Natural Attenuation Capacity of Groundwater Systems. Bioremediation Journal 2(3\&4):227-238 (1998).

Chien YJ and CJ Murray. 2003. "Geostatistical Analysis of Tc-99 Groundwater Monitoring in the 200-BP-5 Operable Unit." Appendix A in Groundwater Sampling and Analysis Plan for the 200-BP-5 Operable Unit. DOE/RL-2001-49, U.S. Department of Energy, Richland Operations Office, Richland, Washington.

Cho JC and JM Tiedje. 2002. "Quantitative Detection of Microbial Genes by Using DNA Microarrays.” Applied and Environmental Microbiology, 68(3):1425-1430.

Clarke, AC. 1983. The Sentinel. Berkeley Publishing Group, Berkeley, California.

Clement TP. 1997. RT3D-A Modular Computer Code for Simulating Reactive Multi-Species Transport in 3-Dimensional Groundwater Aquifers. PNNL-11720, Pacific Northwest National Laboratory, Richland, Washington.

Clements FE. 1920. Plant Indicators: The Relation of Plant Communities to Process and Practice. Carnegie Institution of Washington, Washington, D.C.

Cozarelli IM, BA Bekins, MJ Baedecker, GR Aiken, RP Eganhouse, and ME Tuccillo. 2001.

"Progression of Natural Attenuation Processes at a Crude Oil Spill Site: I. Geochemical Evolution of the Plume." Journal of Contaminant Hydrogeology 5:369-385.

Culler DE and H Mulder. 2004. "Smart Sensors to Network the World." Scientific American, June 2004.

Dennis P, EA Edwards, SN Liss, and R Fulthorpe. 2003. "Monitoring Gene Expression in Mixed Microbial Communities by Using DNA Microarrays." Applied and Environmental Microbiology, V69, N2, p.769-778.

deWit. 1965. Photosynthesis of Leaf Canopies, Agriculture Research Report no. 663, Centre Agr. Publ. Doc., Wageningen, The Netherlands.

DOD. 2004. SERDP \& ESTCP DNAPL Source Zone Initiative: Annual Report. SERDP Program Office, U.S. Department of Defense, Arlington, VA.

DOE. 1998. Innovative Technology Summary Report: Horizontal Wells. DOE/EM-0378, U.S. Department of Energy, Office of Environmental Management, Washington, D.C.

Early, TO, B. Borden, M Heitkamp, BB Looney, D Major, WJ Waugh, G Wein, T Wiedemeier, KM Vangelas, KM Adams, and CH Sink. 2006. Enhanced Attenuation: A Reference Guide on 
Approaches to Increase the Natural Treatment Capacity of a System. WSRC-STI-2006-00083, Rev. 1, U. S. Department of Energy Office of Scientific and Technical Information, Oak Ridge TN.

Echols KR, RW Gale, TR Schwartz, JN Huckins, LL Williams, JC Meadows, D Morse, JD Petty, CE Orazio, and DE Tillitt. 2000. "Comparing Polychlorinate Diphenyl Concentrations and Patterns in the Saginaw River Using Sediment, Caged Fish, and Semipermeable Membrane Devices." Environmental Science and Technology 34:4095-4102.

EPA. 1994. Alternative Methods for Fluid Delivery and Recovery. EPA/625/R-94/003, U.S. Environmental Protection Agency, Office of Research and Development, Washington, D.C.

EPA. 1998. Technical Protocol for Evaluating Natural Attenuation of Chlorinated Solvents in Ground Water. EPA/600/R-98/128, U.S. Environmental Protection Agency, Office of Research and Development, Washington D.C.

EPA. 1999. Use of Monitored Natural. Directive Number 9200.4 17P, U.S. Environmental Protection Agency, Office of Solid Waste and Emergency Response, Washington, D.C.

EPA. 2004a. Performance Monitoring of MNA Remedies for VOCs in Ground Water. EPA 600-R-04-027. U.S. Environmental Protection Agency, Washington, D.C.

EPA. 2004b. "Framework Approach for MNA for Radionuclides and Inorganics in Groundwater." Presented at the workshop: Long-Term Monitoring of Metals and Radionuclides in the Subsurface: Strategies, Tools and Case Studies. April 21-22, 2004, sponsored by the U.S. Geological Survey and the U.S. Department of Energy, Reston Virginia.

EPA. 2004c. Survey of Technologies for Monitoring Containment Liners and Covers. EPA 542-R-04-013, U.S. Environmental Protection Agency, Washington, D.C.

ESTCP. 2004. Demonstration and Validation of a Water and Solute Flux Measuring Device. Environmental Security Technology Certification Program, fact sheet. Available online at http://www.estcp.org/projects/cleanup/200114o.cfm

Gibson TL, AS Abdul, and PD Chalmer. 1998. "Enhancement of In Situ Bioremediation of BTEX-Contaminated Ground Water by Oxygen Diffusion from Silicone Tubing." Ground Water Monitoring and Remediation, Winter, pp. 93-104.

Gilmore TJ. 2001. Micron-sized "Sensors" to Monitor the Environment. IP Services Files No. 12932-B., Pacific Northwest National Laboratory, Richland, Washington.

Gilmore TJ and M Oostrom. 1999. Delivery of Reactants to Groundwater Using Gas Permeable Tubing for Contaminant Remediation. Abstract, American Geophysical Union Fall 1999 Conference, San Francisco, California.

Gossett J. 2002. Fishing for microbes. Science. 298:974-975. 
WSRC-STI-2006-00084, Rev. 1

August 1, 2006

Page 50 of 53

Guilbeault MA, BL Parker, and JA Cherry. 2005. "Mass and Flux Distribution from DNAPL Zones in Sandy Aquifers." Ground Water 43(1):70-86.

Hatfield K, M Annable, JH Cho, PSC Rao, and H Klammler. 2004. "A Direct Passive Method for Measuring Water and Contaminant Fluxes in Porous Media." Journal of Contaminant Hydrology, 75(3-4):155-181.

Herrera, GS, GF Pinder. 2005. Space-time optimization of groundwater quality sampling networks Water Resources Research, Vol. 41, W12407.

Hurt RA, XY Qiu, LY Wu, Y Roh, AV Palumbo, JM Tiedje, and JH Zhou. 2001.

"Simultaneous Recovery of RNA and DNA from Soils and Sediments." Applied and Environmental Microbiology 67 (10):4495-4503.

ITRC. 2004. Technical and Regulatory Guidelines for Strategies for Monitoring the Performance of DNAPL Source Zone Remedies. Interstate Technology \& Regulatory Council.

Johnson, BT, JD Petty, JN Huckins, K Lee, and J Gauthier. 2004. "Hazard Assessment of a Simulated Oil Spill on Intertidal Areas of the St. Lawrence River with SPMD-TOX." Environmental Toxicology 19 (4):329-335.

Kearl PM and CM Case. 1992. "Direct Field Measurement of Groundwater Velocities." Interdisciplinary Approaches in Hydrology and Hydrogeology, American Institute of Hydrology, pp 91-102.

Kearl PM, FG Gardner, and MJ Gunderson. 1993. Groundwater Flow Delineation Study at the Massachusetts Military Reservation Using the Colloidal Borescope. ORNL/TM-12139, Oak Ridge National Laboratory, Oak Ridge, Tennessee.

Kerfoot WB and VA Massard. 1985. "Monitoring Well Screen Influence on Direct Flowmeter Measurements." Ground Water Monitoring Review. 5(4):74-77

Kerfoot WB. 1988. "Monitoring Well Construction and Recommended Procedures for Direct Ground-Water Flow Measurements Using a Heat-Pulsing Flowmeter." In Ground-water Contamination: Field Methods. A.G. Collins and A.I. Johnson (eds.), American Society for Testing and Materials, Philadelphia. ASTM STP 963, pp. 146-191

Krause GH and E Weis. 1984. "Chlorophyll Fluorescence as a Tool in Plant Physiology; Interpretation of Fluorescence Signals.” Photosynthesis Research 5(2):139-157.

Loaiciga HA, RJ Charbeneau, LG Everett, GE Goff, BF Hobbs, and S Rouhani. 1992. "Review of Ground-Water Quality Monitoring Network Design.” ASCE Journal of Hydraulic

Engineering 118(1):11-37. 
Looney, BB, FH Chapelle, TO Early, KM Vangelas, KM Adams, and CH Sink. 2006. Mass Balance: A Key to Advancing Monitored and Enhanced Attenuation for Chlorinated Solvents. WSRC-STI-2006-00082, Rev. 0, U. S. Department of Energy Office of Scientific and Technical Information, Oak Ridge TN.

Lorah M. 2002. "Natural Attenuation of Chlorinated Aliphatics in Wetlands: Linking Hydrology, Geochemistry, and Microbiology." Presented at the Summary of the Remediation Technologies Development Forum Sediments Remediation Action Team Meeting, October 2930, 2002, Seattle, Washington.

Lefkovitz, L, E Crecelius, and N McElroy. 1996. "The Use of Polyethylene Alone to Predict Dissolved-Phase Organics in the Columbia River." Presented at the Society of Environmental Toxicology and Chemistry, November 17-21, 1996, Washington, DC.

Lu X., J.T. Wilson, and D.H. Kampbell. 2004. Relationship between Dehalococcoides DNA and Dechlorination Rates at Field Scale. Forth international conference, Remediation of Chlorinated and Recalcitrant Compounds, Monterey, California.

Major D.W., M.Heitkamp, C.Bagwell, and C.H.Sink. 2004. Advances in Molecular Technologies: Putting the Third Line of Evidence First. Forth international conference, Remediation of Chlorinated and Recalcitrant Compounds, Monterey, California.

McNaughton and Jarvis. 1983. "Predicting Effects of Vegetation Changes on Transpiration and Evaporation," in T.T. Kozlowski (ed.), Water Deficits and Plant Growth, Vol. VII, pp. 1-47, Academic Press, New York.

Minsker, B (Ed.). 2003. Long-Term Groundwater Monitoring: The State of the Art, Am. Soc. of Civ. Eng., Reston, Va.

Meyer PD. 1993. A Quantitative Method for Groundwater Surveillance Monitoring Network Design at the Hanford Site. PNL-8868, Pacific Northwest Laboratory, Richland, Washington.

Minnesota Pollution Control Agency. 1999. Guidelines Natural Attenuation of Chlorinated Solvents in Ground Water. Minnesota Pollution Control Agency, Site Remediation Section, St. Paul, Minnesota.

Naudet V. A. Revil, and J.-Y.Bottero. 2003. Relationship between self-potential (SP) signals and redox conditions in contaminanted groundwater. Geophysical Research Letters, 30(21):2091.

Newell CJ, HS Rifai, JT Wilson, JA Connor, CE Aziz, and MP Suarez. 2002. Calculation and Use of First-Order Rate Constants for Monitored Natural Attenuation Studies. EPA/540/S02/500, U. S. Environmental Protection Agency, Washington, DC. 
Portnoy JW, BL Nowicki, CT Roman, and DW Urish. 1998. "The Discharge of NitrateContaminated Groundwater from Developed Shoreline to Marsh-Fringed Estuary." Water Resour. Res. 34:3095.

RCRA - Resource Conservation and Recovery Act. 1976. Public Law 94-580, as amended, 90 Stat. 2795, 42 USC 6901 et seq.

Reed, P, B Minksker, and AJ Valocchi. 2000. Cost-effective long-term groundwater montoring design using a genetic algorithm and global mass interpolation. Water Resour. Res., 36(12):3731-3741.

Reiss R., C. Hardison, and P. Guerra. 2004. Application of Proteomics to Monitor the Intrinsic biodegradation of 1,2-Dichloroethane. Forth international conference, Remediation of Chlorinated and Recalcitrant Compounds, Monterey, California.

Richter PI, A Barocsi, Z Csintalan, MJ Kuperberg, and J Szdzuj. 1998. "Monitoring Soil Phytoremediation by a Portable Chlorophyll Fluorometer." Field Analytical Chemistry and Technology 2(4):241-249.

Ross. 1981. The Radiation Regime and Architecture of Plant Stands, Junk, The Hague. SERDP. 2005. SERDP and ESTCP Expert Panel Workshop on Research and Development Needs for the Environmental Remediation Application of Molecular Biological Tools. Final Report October 2005.

Sauck W. 1998. "A Conceptual Model for the Geoelectrical Response of LNAPL Plumes in Granular Sediments.” SAGEEP 1998 Proceedings, 805-817.

Sauck W. 2000. "A Model for the Resistivity Structure of LNAPL Plumes and Their Environs in Sand Sediments.” J. Appl. Geophys. 44:151-66.

Schena M, D Shalon, RW Davis, and PO Brown. 1995. "Quantitative Monitoring of Gene Expression Patterns with a Complementary DNA Microarray." Science 270:5235, 467-470.

Siemens. 1998. Leos Leak Detection and Location System. Siemens AG, Bereich Power Generation KWU NW-D, Erlangen, Germany.

Torgersen CE, RN Faux, BA McIntosh, NJ Poage, and DJ Norton. 2001. "Airborne Thermal Remote Sensing for Water Temperature Assessment in Rivers and Streams." Remote Sensing of Environment 76:386-398.

Torsvik, V., J. Goksoyr, and F.L. Daae. 1990. High diversity of DNA of soil bacteria. Applied and Environmental Microbiology. 56:782-787.

Torsvik V, FL Daae, RA Sandaa, and L Ovreas. 1998. "Novel Techniques for Analyzing Microbial Diversity in Natural and Perturbed Environments." Journal of Biotechnology, 64(1):53-62. 
WSRC-STI-2006-00084, Rev. 1

August 1, 2006

Page 53 of 53

Truex MJ, CD Johnson, JR Spencer, and TP Clement. 2002. "Evaluating Natural Attenuation of Chlorinated Solvents At A Complex Site." In Proceedings of the Third International Conference on Remediation of Chlorinated and Recalcitrant Compounds, May 20-23, 2002, Monterey, California.

Vanhala H. 1997. "Mapping oil contaminated sands and tills with the spectral induced polarization (SIP) method." Geophysical Prospecting 45, 303-326.

Versteeg R. 2005. "Geophysical methods for performance monitoring of contaminant remediation" Department of Energy's Performance Monitorng Workshop, June21-23, 2005, Butte, Montana.

Wang Z, Y Wang, M Ma, Y Lu, and J Huckins. 2002. "Use of Triolein-Semipermeable Membrane Devices to Assess the Concentration and Sediment Sorption of Hydrophobic Organic Contaminants in the Huaihe River, China." Environmental Toxicology and Chemistry 21(11):2378-2384.

Waugh, W.J., and G. VanReyper. 2003. Technologies for Evaluating Plant Health and Phytoremediation of Ground Water at the U.S. Department of Energy Moab, Utah, Site. GJO2003-407-TAC, Environmental Sciences Laboratory, U.S. Department of Energy, Grand Junction, CO.

Werkema DD. 2002. Geolectrical Response of an Aged LNAPL Plume: Implications of Monitoring Natural Attenuaton. PhD thesis, Western Michigan University, Kalamazoo, Michigan.

Wilson BH, JT Wilson, and D Luce. 1996. Design and Interpretation of Microcosm Studies for Chlorinated Compound. EPA/600/A-96/093, U.S. Environmental Protection Agency, Washington, DC.

Wilson RD and DM Mackay. 1995. "A Method for Passive Release of Solutes from an Unpumped Well.” Ground Water 33(6):936-945.

Wu W, SE Wildsmith, AJ Winkley, R Yallop, FJ Elcock, and PJ Bugelski. 2001. "Chemometric Strategies for Normalization of Gene Expression Data Obtained from cDNA Microarrays." Analytica Chimica Acta 446 (1-2): 451-466. 